Aus der Abteilung Psychiatrie und Psychotherapie

(Prof. Dr. med. P. Falkai)

im Zentrum Psychosoziale Medizin

der Medizinischen Fakultät der Universität Göttingen

\title{
Pathologische Veränderungen im Thalamus in einem Tiermodell für die Alzheimer-Krankheit
}

\author{
INAUGURAL-DISSERTATION \\ zur Erlangung des Doktorgrades \\ der Medizinischen Fakultät \\ der Georg-August-Universität zu Göttingen \\ vorgelegt von \\ Johann-Christian Antonius Flohr \\ aus Berlin
}

Göttingen 2009 
Dekan:

1. Berichterstatter:

2.Berichterstatter/in:

3. Berichterstatter/in:
Prof. Dr. med. C. Frömmel

Prof. Dr. rer. nat. T. Bayer

Tag der mündlichen Prüfung: 
Teile dieser Arbeit wurden bereits in folgender Publikation veröffentlicht:

Christensen DZ, Kraus SL, Flohr A, Cotel MC, Wirths O und Bayer TA (2008b): Transient intraneuronal $A$ beta rather than extracellular plaque pathology correlates with neuron loss in the frontal cortex of APP/PS1KI mice. Acta Neuropathol 116, 647-55 


\section{Inhaltsverzeichnis}

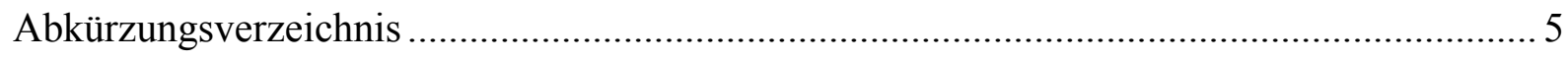

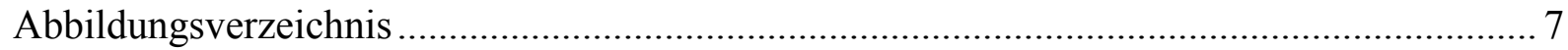

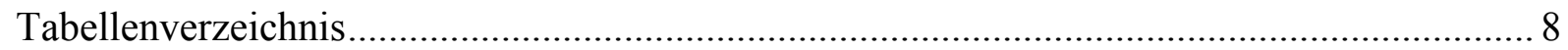

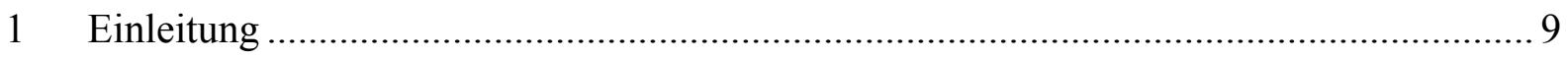

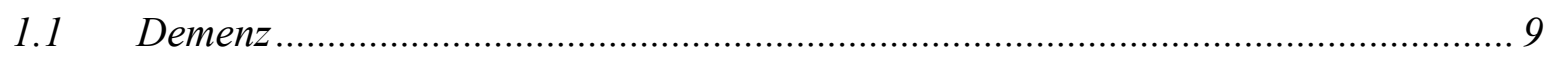

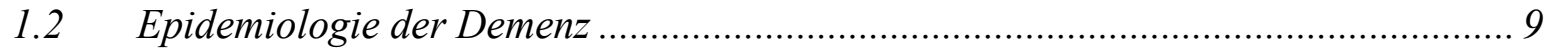

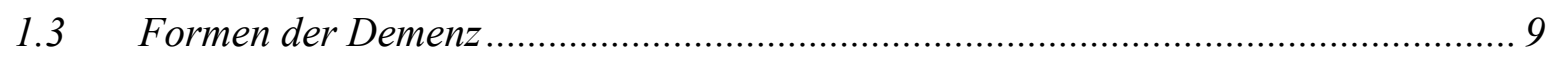

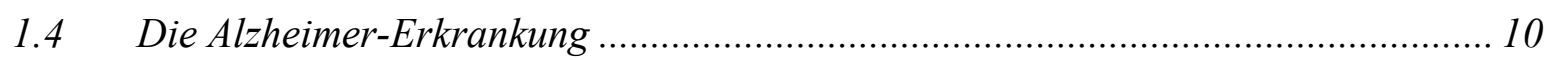

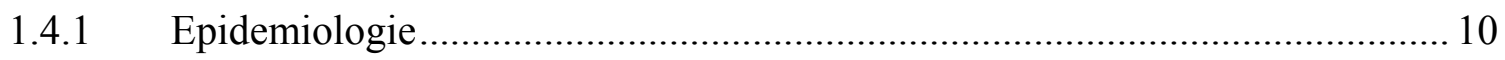

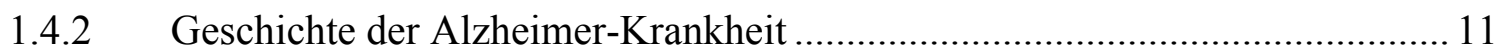

1.4.3 Klinischer Verlauf und Stadien .................................................................... 11

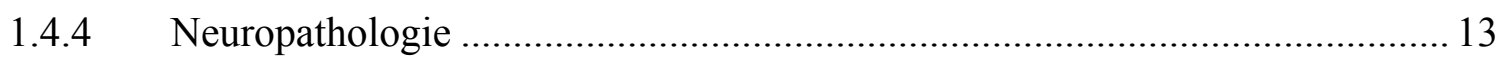

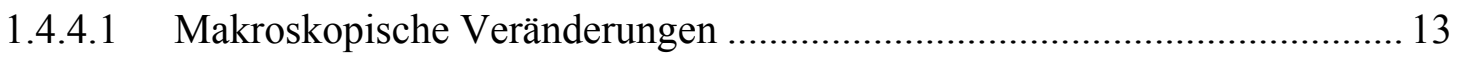

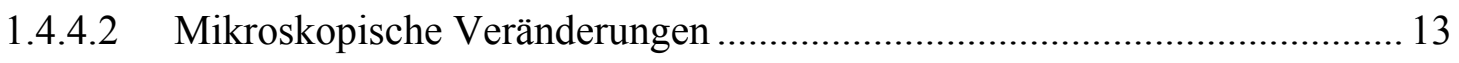

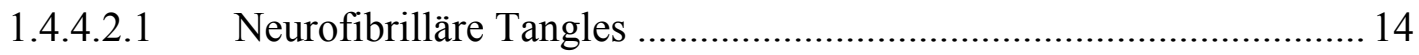

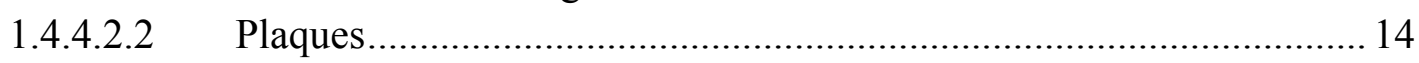

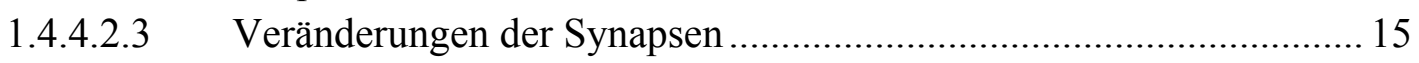

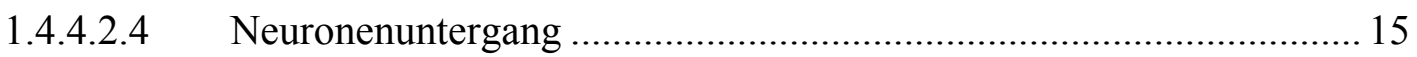

1.4.5 Risikofaktoren und Prädispositionen der Alzheimer-Erkrankung..................... 16

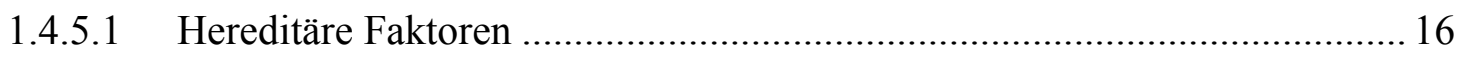

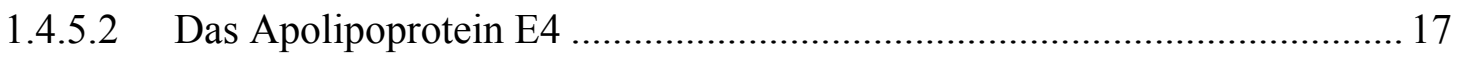

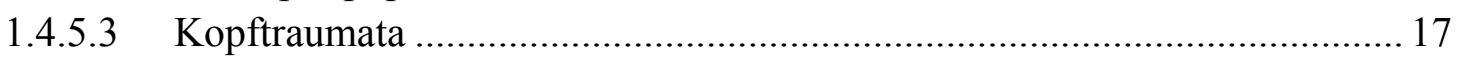

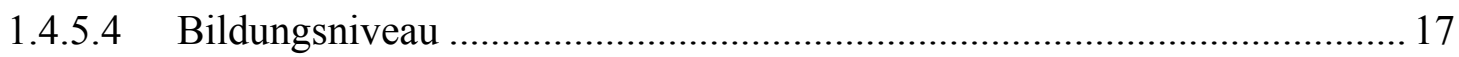

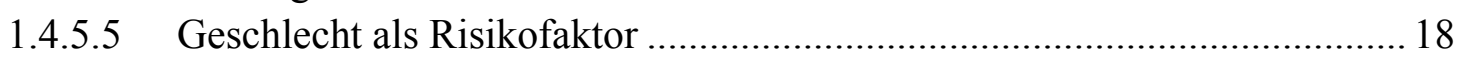

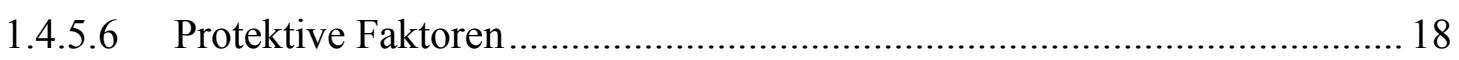

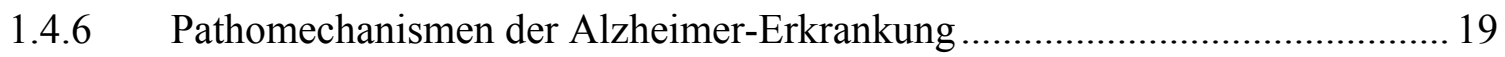

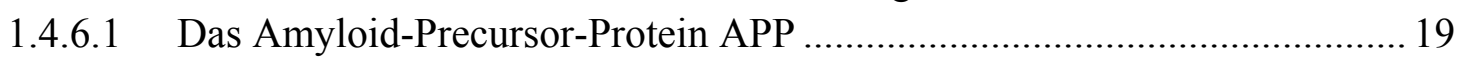

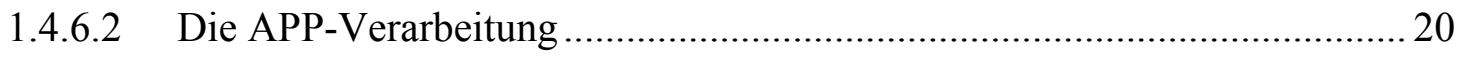

1.4.6.3 Die Hypothese der $\beta$-Amyloid-Kaskade .................................................. 20

1.4.7 Mausmodelle in der Alzheimer-Forschung .................................................... 22

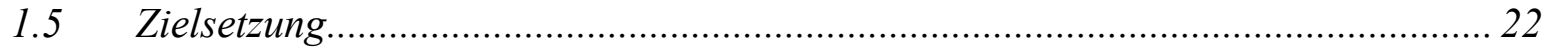

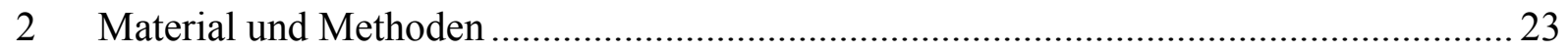

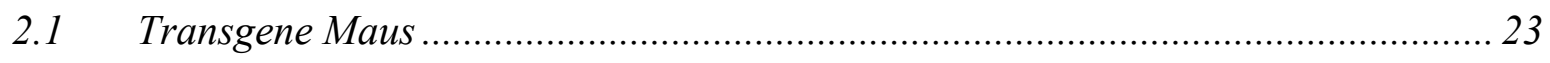

2.2 Gewinnung und Aufbereitung des Hirngewebes ................................................ 23

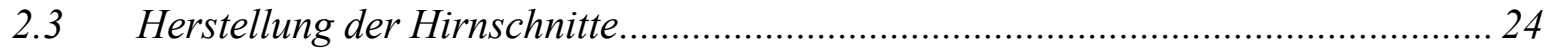

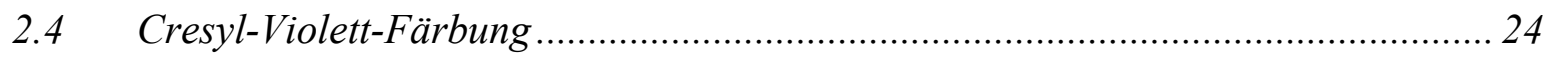




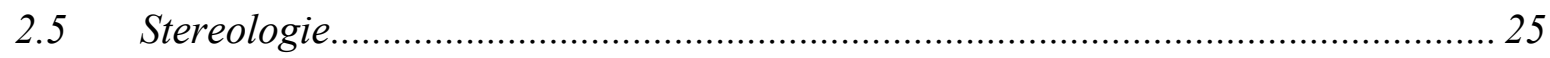

2.6 Immunhistochemische Färbung der Paraffinschnitte ........................................... 28

$2.7 \quad$ A

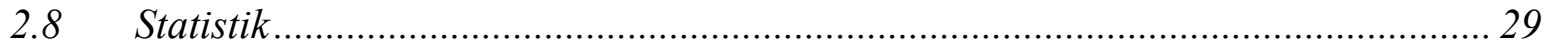

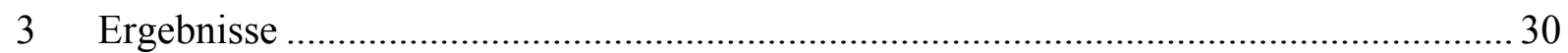

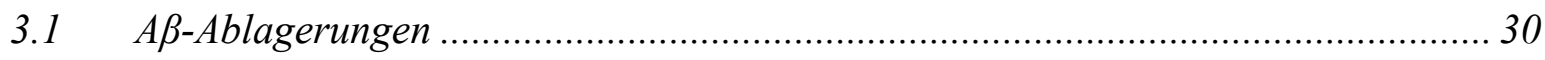

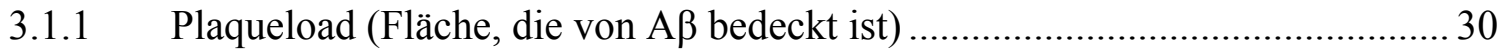

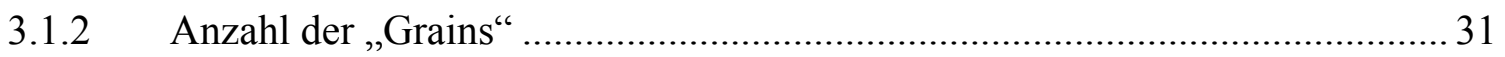

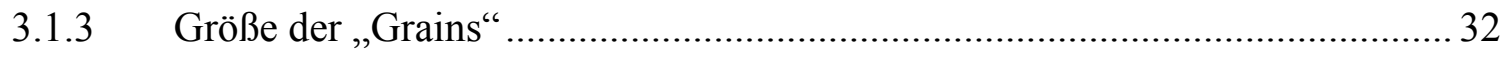

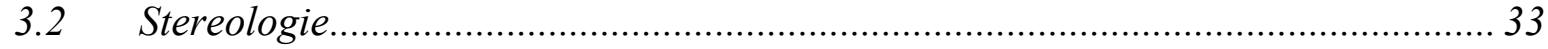

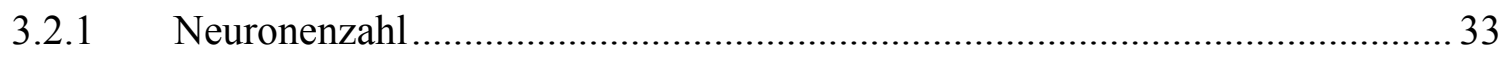

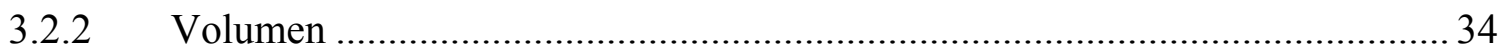

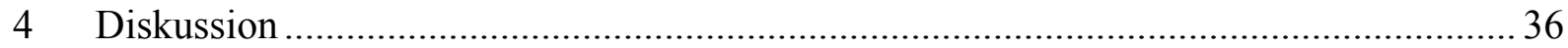

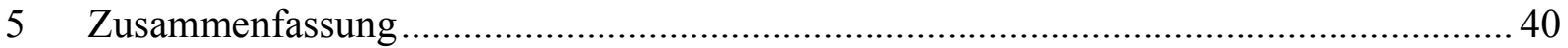

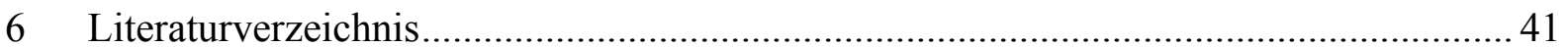




\section{Abkürzungsverzeichnis}

$\mathrm{A} \beta \quad \beta$-Amyloid

$\mathrm{AD}$

Alzeimer's disease /Alzheimer-Demenz

ADAM

A Disintegrin And Metalloprotease

ApoE

Apolipoprotein E

APP

Amyloid-Precursor-Protein (Amyloid-

Vorläuferprotein)

bzw.

beziehungsweise

CA

Cornu ammonis (Ammonshorn)

ca.

circa

CD45

Cluster of Differentiation („Pan-

Leukozytenmarker")

DAB

Diaminobenzidin

DIMDI

Deutsches Institut für Medizinische

Dokumentation und Information

FAD

Familiäre Form der Alzheimer-Demenz

FSH

Follikelstimulierendes Hormon

HET

Hormonersatztherapie

ICD-10-GM

International Classification of Diseases, $10^{\text {th }}$

Revision, German Modification

LH

Luteinisierendes Hormon

NSAID

Nonsteroid Anti Inflammatory Drugs

PBS

Phosphate Buffered Saline (Phosphat-gepufferte

Kochsalzlösung)

PFA

Paraformaldehyd 
PHF

PS1

PS2

TACE
Paired Helical Filaments (Gepaarte helikale Filamente)

Presenilin-1-Gen

Presenilin-2-Gen

Tumor Necrosis Factor $\alpha$ Converting Enzyme 


\section{Abbildungsverzeichnis}

Abbildung 1 Auguste Deter aus Frankfurt am Main wurde von Alois Alzheimer als erste Alzheimer-Patientin beschrieben (Alzheimer 1907).

Abbildung 2 links: Gehirn eines Alzheimer-Erkrankten (Böcker et al. 2004); rechts gesundes Gehirn (Blöchlinger 2007)

Abbildung 3 Neurofibrilläre Tangles, gezeichnet von Alois Alzheimer anhand seiner Patientin Aguste D.(Verhey 2006)

Abbildung 4 Plaques im Neuropil angefärbt mit einem Antikörper gegen $\beta$-Amyloid (Christensen et al. 2008b).

Abbildung 5 Zwei verschiedene Wege der posttranslationalen Prozessierung des APP, modifiziert nach www.fbs.leeds.ac.uk (2009)

Abbildung 6 Die $\beta$-Amyloid-Kaskaden-Hypothese nach Hardy und Allsop (Hardy und Allsop 1991).

Abbildung 7 Die modifizierte $\beta$-Amyloid-Kaskaden-Hypothese nach Wirths et al. (2004)

Abbildung 8 Schematische Darstellung des Thalamus von Bregma -0,94 bis -2,54, erstellt mit „The mouse brain in stereotaxic coordinates“ (Paxinos und Franklin 2001) . 27

Abbildung 9 Plaqueload im Thalamus in Prozent Fläche der Gesamtfläche bei zwei und sechs Monate alten Mäusen.

Abbildung 10 Plaqueload im Thalamus und Frontalkortex in Prozent Fläche der Gesamtfläche bei zwei, sechs und zwölf Monate alten Mäusen. *** $\mathrm{P}<0,001$; ** $\mathrm{P}<0,01 ; * \mathrm{P}<0,05$

Abbildung 11 Anzahl der gemessenen „Grains“ pro $\mathrm{mm}^{2}$ im Thalamus im Alter von zwei und sechs Monaten.

Abbildung 12 „Grains“ pro $\mathrm{mm}^{2}$ im Thalamus und Frontalkortex bei zwei, sechs und zwölf Monate alten Mäusen. ** $\mathrm{P}<0,01 ; * \mathrm{P}<0,05$

Abbildung 13 Durchschnittliche Größe der angefärbten A $\beta$-Ablagerungen im Thalamus im Alter von zwei und sechs Monaten.

Abbildung 14 Durchschnittliche Größe der angefärbten A $\beta$-Ablagerungen im Thalamus und Frontalkortex im Alter von zwei , sechs und zwölf Monaten. 
Abbildung 15 Anzahl der Neurone im Thalamus der Mäuse mit den verschiedenen Genotypen PS1KI und APP/PS1KI im Alter von zwei, sechs und zwölf Monaten.

Abbildung 16 Anzahl der Neurone im Frontalkortex der Mäuse mit den verschiedenen Genotypen PS1KI und APP/PS1KI im Alter von zwei, sechs und zwölf Monaten.

Abbildung 17 Volumina des Thalamus der zwei verschiedenen Genotypen PS1KI und APP/PS1KI zu den Zeitpunkten zwei, sechs und zwölf Monate.

Abbildung 18 Volumina des Frontalkortex der zwei verschiedenen Genotypen PS1KI und APP/PS1KI zu den Zeitpunkten zwei, sechs und zwölf Monate.

\section{Tabellenverzeichnis}

Tabelle 1: Übersicht der untersuchten Mäuse.

Tabelle 2: Gewählte Parameter im Stereo Investigator. 


\section{Einleitung}

\subsection{Demenz}

Die Demenz ist definiert als eine chronisch, über Monate bis Jahre, fortschreitende degenerative Erkrankung, die mit dem Verlust von früher erworbenen kognitiven Fähigkeiten einhergeht (Pschyrembel 2007, S. 403).

Nach der ICD-10-GM ist die Demenz „...ein Syndrom als Folge einer meist chronischen oder fortschreitenden Krankheit des Gehirns mit Störung vieler höherer kortikaler Funktionen, einschließlich Gedächtnis, Denken, Orientierung, Auffassung, Rechnen, Lernfähigkeit, Sprache und Urteilsvermögen. Das Bewusstsein ist nicht getrübt. Die kognitiven Beeinträchtigungen werden gewöhnlich von Veränderungen der emotionalen Kontrolle, des Sozialverhaltens oder der Motivation begleitet, gelegentlich treten diese auch eher auf. Dieses Syndrom kommt bei AlzheimerKrankheit, bei zerebrovaskulären Störungen und bei anderen Zustandsbildern vor, die primär oder sekundär das Gehirn betreffen.“ (DIMDI 2009).

\subsection{Epidemiologie der Demenz}

In Deutschland leiden 250 von 100.000 Menschen an einer Demenz. Das entspricht einer Prävalenzrate von $0,25 \%$. Pro Jahr gibt es 50 Neuerkrankungen auf 100.000 Einwohner, was einer Inzidenzrate von $0,05 \%$ entspricht. Bei den über 65-Jährigen sind sogar mehr als 5\% betroffen. Von allen dementiellen Syndromen macht die Alzheimer-Erkrankung mit 60\% den größten Anteil aus. Aufgrund der höheren Lebenserwartung sind Frauen im höheren Maße betroffen als Männer (Masuhr und Neumann 2007).

Anhand von Bevölkerungsberechnungen gibt es Schätzungen der in der Zukunft zu erwartenden Prävalenzraten für Deutschland. Die Grundlage dieser Schätzungen sind die über 65-Jährigen bei gleich bleibenden altersspezifischen Prävalenzraten. Es wird angenommen, dass sich die Zahl der Demenzkranken von derzeit ca.1,2 Millionen bis 2050 verdoppelt (Weyerer 2005).

\subsection{Formen der Demenz}

Demenzen lassen sich in primäre und sekundäre Formen einteilen. Sekundäre Demenzen sind Folge einer Grunderkrankung, z.B. kardiovaskuläre Erkrankungen, 
Alkoholabusus, Hydrocephalus malresorptivus, Hyperthyreose, VitaminmangelErkrankungen oder auch als Nebenwirkungen von Medikamenten. Insgesamt sind die sekundären Demenzen seltener und in manchen Fällen auch reversibel.

Primäre Formen der Demenz sind vergleichsweise häufig und werden in zwei Gruppen aufgeteilt: vaskuläre und degenerative Demenzen. Erstere machen etwa 16\% aus. Die degenerativen Formen sind die häufigsten Demenzen. Die ParkinsonSyndrom-assoziierte Demenz macht $6 \%$ aus und andere Formen zusammen noch etwa 5\%. Die am häufigsten vorkommende Demenzform ist die vom Alzheimer-Typ mit $72 \%$ (Ott et al. 1995).

\subsection{Die Alzheimer-Erkrankung}

\subsubsection{Epidemiologie}

In der Bundesrepublik Deutschland leben ca. 650.000 Menschen, welche an der Alzheimer-Erkrankung leiden. Von den jährlich 200.000 Neuerkrankungen an Demenz sind 120.000 vom Alzheimer-Typ. Aufgrund der höheren Lebenserwartung von Frauen sind 70\% der Alzheimer-Patienten weiblich. Anhand der zunehmenden Prävalenzrate mit steigendem Lebensalter lassen sich verschiedene Gruppen unterscheiden. Die über 80-Jährigen machen zwei Drittel der Prävalenz und 60\% der jährlichen Inzidenz aus, die Altersgruppe der unter 65-Jährigen hat Raten von weniger als 3\% (Bickel 2000). 


\subsubsection{Geschichte der Alzheimer-Krankheit}

Der fortschreitende geistige Verfall im Alter wurde immer wieder in der Geschichte erwähnt. Doch erst 1907 beschreibt der Arzt Dr. Alois Alzheimer (1864-1915) das Krankheitsbild anhand einer Frau, die bis $\mathrm{zu}$ ihrem Tod jahrelang an

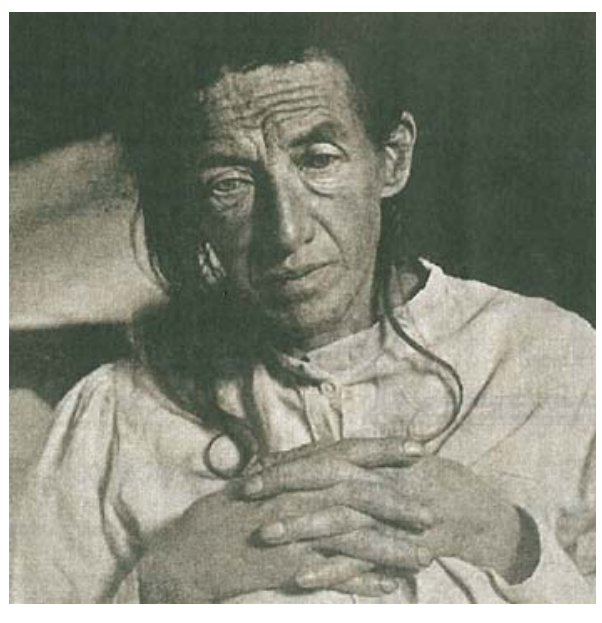
Gedächtnisproblemen, Verwirrtheit und Kommunikationsproblemen litt. In der nach Ihrem Tod durchgeführten Autopsie beschreibt Alois Alzheimer erstmals die Eiweißablagerungen zwischen den Zellen (Plaques) und in den Nervenzellen (Fibrillen) des Gehirns. Heute trägt dieses Krankheitsbild seinen Namen: Morbus Alzheimer oder AlzheimerDemenz (www.alzheimer-forschung.de 2009).

Abbildung 1 Auguste Deter aus Frankfurt am Main wurde von Alois Alzheimer als erste Alzheimer-Patientin beschrieben (Alzheimer 1907).

\subsubsection{Klinischer Verlauf und Stadien}

Die Alzheimer-Erkrankung ist ein chronisch progredient verlaufendes Krankheitsbild. Kognitive Fähigkeiten gehen verloren, was dazu führt, dass die Betroffenen sich nicht mehr selber versorgen können. Im Verlauf wird eine dauerhafte Betreuung und Pflege unerlässlich.

Die Erkrankung wird klinisch in drei Phasen eingeteilt, wobei die Übergänge fließend sind und Mischformen häufig vorkommen.

1. Das Frühstadium ist gekennzeichnet durch die Beeinträchtigung des Kurzzeitgedächtnisses. Eben genannte Namen werden vergessen, Termine werden versäumt und es fällt dem Betroffenen schwer, einer Unterhaltung inhaltlich zu folgen. Wortspiele werden nach langem Überlegen oder gar nicht verstanden und der Patient verwendet selber eine einfache Sprache.

Die Orientierung in neuen Umgebungen kann Probleme bereiten. Auch das Zeitgefühl kann sich verschlechtern. Dies kann bedeuten, dass die Ausübung des Berufes nur noch eingeschränkt oder gar nicht mehr möglich ist. Sogar das eigene Ankleiden kann zur alltäglichen Hürde werden. 
All diese Probleme werden bei vollem Bewusstsein wahrgenommen und können zu Scham, Wut, Angst oder auch Frustration führen. Viele Patienten ziehen sich deshalb zurück und versuchen die Probleme zu überspielen.

2. Die zweite Phase der Erkrankung ist gekennzeichnet durch eine notwendig gewordene Unterstützung im Alltag. Alle Symptome der ersten Phase sind nun ausgeprägter vorhanden. Dazu kommt eine Beeinträchtigung des Langzeitgedächtnisses. Namen von Angehörigen oder Vertrauten können nicht mehr genannt werden. Es kann zu häufigen Wiederholungen von Wörtern oder auch Sätzen kommen. Die Orientierung in vertrauter Umgebung kann so gestört sein, dass sich die Patienten im eigenen Haus verirren. Aufgrund der Orientierungsstörungen und einer hinzukommenden Unruhe kann es passieren, dass Betroffene davonlaufen.

Stimmungsschwankungen sind häufig und gehen von einem Extrem (Aggression) in ein anderes Extrem über (Rückzug). Der Tag-Nacht-Rhythmus geht verloren und die Kontrolle über Harn und Stuhl kann gestört sein. Trotz der enormen Hilfebedürftigkeit kann es Momente geben, in denen die Betroffenen normal wirken.

3. Im Spätstadium der Alzheimer-Erkrankung ist eine durchgehende Betreuung und Pflege notwendig. Neue Informationen können nicht mehr aufgenommen werden und die eigene Sprache ist auf wenige Wörter begrenzt.

Stimmungsschwankungen werden in dieser Phase seltener, jedoch wird die Kontrolle über den eigenen Körper immer schwieriger. Insgesamt ist der motorische Antrieb stark vermindert, sodass die Patienten sich kaum noch aus eigenem Antrieb bewegen. Die Mimik verschwindet, Blase und Darm entziehen sich der Kontrolle des Patienten und es kommen Störungen des Schluckreflexes hinzu. Eventuell treten Krampfanfälle auf. Zuletzt geht die Wahrnehmung des eigenen Körpers verloren und die Erkrankten werden teilnahmslos.

Die Dauer der einzelnen Phasen ist sehr variabel und der Tod tritt nicht durch die Grunderkrankung Alzheimer ein. Oft sterben die Patienten an Begleiterkrankungen wie etwa einer Lungenentzündung als Folge einer Nahrungsmittelaspiration (www.alzheimer.de 2009). 


\subsubsection{Neuropathologie}

Die Alzheimer-Erkrankung betrifft hauptsächlich ältere Menschen. Deshalb sind neben den typischen Alzheimer-Neuropathologien auch physiologisch vorkommende Veränderungen im Gehirn eines alten Menschen vorzufinden. So sind bei NichtAlzheimer-Erkrankten milde Gehirnatrophie, Plaques und wenige Fibrillen in Neokortex, entorhinaler Region und Hippokampus beschrieben (Hof et al. 1996).

Die typischen Veränderungen am Gehirn durch die Alzheimer-Demenz lassen sich auf der makroskopischen und mikroskopischen Ebene betrachten.

\subsubsection{Makroskopische Veränderungen}

In späten Stadien der Alzheimer-Erkrankung findet sich eine ausgeprägte kortikal betonte Gehirnatrophie (Böcker et al. 2004). Die Gyri sind verschmälert und die Sulci verbreitert. In frühen Stadien kann diese Morphologie fehlen, sodass eine bildgebende Diagnostik wenig Aussagekraft hat bezüglich der Alzheimer-Demenz.
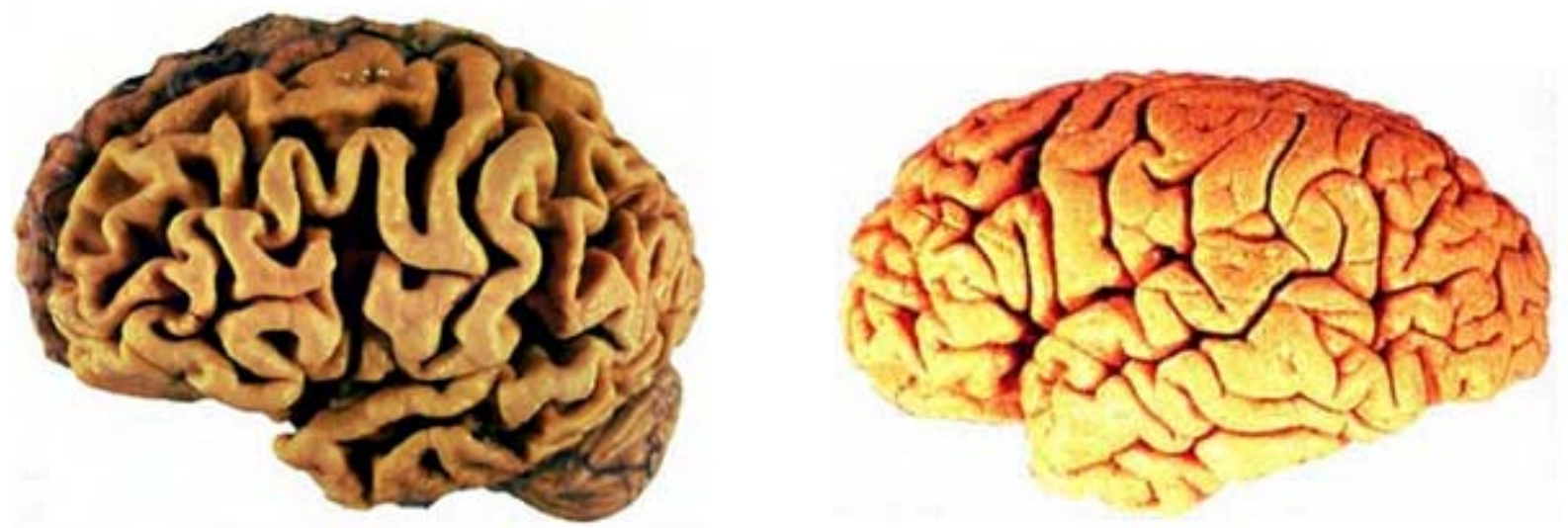

Abbildung 2 links: Gehirn eines Alzheimer-Erkrankten (Böcker et al. 2004, S. 308); rechts: gesundes Gehirn (Blöchlinger 2007)

\subsubsection{Mikroskopische Veränderungen}

Schon Alois Alzheimer beschrieb an seinen Patienten die für die Alzheimer-Krankheit typischen, mikroskopischen Veränderungen. Er stellte fest, dass Plaques und Neurofibrillen in stärkerem Ausmaß in AD-Gehirnen zu finden waren. Andererseits sind Fälle beschrieben, bei denen hohe Konzentrationen von Plaques gefunden wurden, aber keine, für die Alzheimer-Erkrankung typischen Symptome zu Lebzeiten vorlagen (Katzman et al. 1988). Auch ist beschrieben, dass es Alzheimer-Erkrankte gibt, bei denen nur geringe Mengen von Neurofibrillen gefunden wurden (Terry et al. 1987). 


\subsection{Neurofibrilläre Tangles}

Die Neurofibrillen oder auch Tangles sind fadenförmige Strukturen, welche besonders perinukleär in den Neuronen von AD-Gehirnen $\mathrm{zu}$ finden sind.

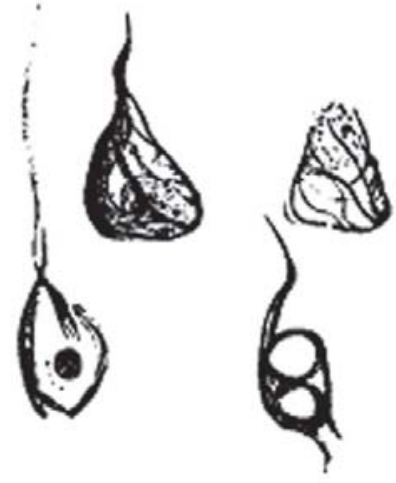
Elektronenmikroskopisch zeigt sich, dass sie als paarige, ca. $10 \mathrm{~nm}$ lange Helices angeordnet sind (gepaarte helikale Filamente, PHF). Zum Teil findet man zusätzlich nicht-helikale Neurofibrillen mit einer Länge von ca. 10$15 \mathrm{~nm}$. Der Grundbaustein der PHF ist abnorm phosphoryliertes Tau-Protein, welches Mikrotubuli-assoziiert ist (Selkoe 2001).

Abbildung 3 Neurofibrilläre Tangles, gezeichnet von Alois Alzheimer anhand seiner Patientin Aguste D.(Verhey 2006, S. 2881)

\subsection{Plaques}

Es gibt zwei Arten von Plaques. Die zuerst beschriebenen neuritischen Plaques lassen sich gut mit Versilberungstechniken darstellen. Die später beschriebenen „diffusen“ oder „präamyloiden“ Plaques wurden erst mit Hilfe von Antikörperfärbetechniken (gegen $\mathrm{A} \beta$ ) entdeckt.

Neuritische Plaques sind im Neuropil gelegene konzentrische extrazelluläre Ablagerungen von $\beta$-Amyloid. Im Zentrum befindet sich ein Amyloidkern, der von einem Bereich, bestehend aus degenerierten Neuriten und Astrozytenfortsätzen, umgeben ist. In der Kernzone und direkt an ihn angrenzend, findet sich Mikroglia, die an ihrer Oberfläche CD45 exprimiert.

Als herausgefunden wurde, dass $\beta$-Amyloid ein Hauptbestandteil von Plaques ist, wurden Färbungen mit Hilfe von Antikörpern durchgeführt, welche gegen $\beta$-Amyloid gerichtet waren. Dabei wurden Ablagerungen gefunden, die weniger dicht und weniger kompakt waren, und weniger fibrilläre Strukturen enthielten als die neuritischen Plaques. Da man davon ausgeht, dass sie eine Vorstufe der eigentlichen Plaques bilden, nennt man sie ,präamyloide“ Plaques. In der direkten Umgebung dieser „diffusen“ Plaques finden sich weniger pathologisch veränderte Dendriten von Neuronen und Gliazellen als in dem Bereich um eine neuritische Plaque. 


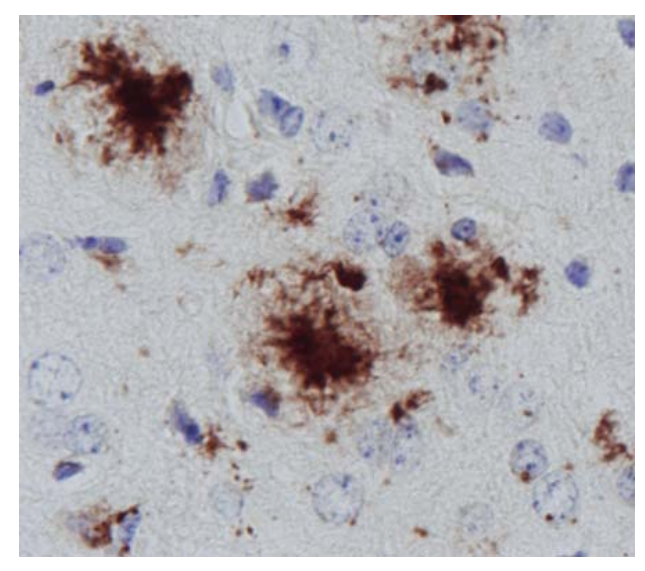

Die Zeit bis zur Entstehung einer Plaque ist unbekannt. Es wird angenommen, dass dies Monate bis Jahre dauert. Die Größe von einzelnen Plaques ist sehr variabel. Kleine Durchmesser von $10 \mu \mathrm{m}$ kommen genauso vor wie große von über $120 \mu \mathrm{m}$. Auch die Dichte und Kompaktheit kann sehr variieren (Selkoe 2001; Böcker et al. 2004).

Abbildung 4 Plaques im Neuropil angefärbt mit einem Antikörper gegen $\beta$-Amyloid (Christensen et al. 2008b, S.650).

\subsection{Veränderungen der Synapsen}

Quantitative Analysen haben ergeben, dass die Dichte von präsynaptischen Markern im Kortex in Postmortemhirngewebe von AD-Erkrankten geringer ist als bei NichtErkrankten (Davies et al. 1987; Honer et al. 1992). Andere Untersuchungen ergaben auch einen Dichteverlust von präsynaptischen Markerproteinen bei AlzeimerErkrankten im hippokampalen Bereich, besonders im Gyrus dentatus (Hamos et al. 1989). Zusätzlich zeigten Immunoblots einen quantitativen Verlust von präsynaptischen Markern wie Synaptin/Synaptophysin (Weiler et al. 1990). Der Verlust von Synapsen ist nicht gleichmäßig in den verschiedenen Hirnarealen. So zeigen Untersuchungen mit dem synaptischen Marker EP10 regionale Unterschiede der Synapsendichte bei Alzheimer-Patienten (Honer et al. 1992). Die Verminderung der Synapsendichte ist nicht allein auf einen Neuronenuntergang zurückzuführen, sondern kommt $\mathrm{zu}$ diesem hinzu. Klinisch führt der Synapsenverlust $\mathrm{zu}$ dem beschriebenen Verlust der kognitiven Leistungen (Coleman und Yao 2003).

\subsection{Neuronenuntergang}

Bereits die orientierend lichtmikroskopische Betrachtung des Neokortex von Alzheimer-Erkrankten zeigt eine verminderte Neuronenzahl. Genaue Quantifizierungen werden mit bildgebenden und stereologischen Verfahren durchgeführt.

Der Neuronenuntergang ist nicht gleichmäßig im Gehirn eines AD-Patienten verteilt. Betroffen sind der Nucleus basalis Meynert (Vogels et al. 1990), der Locus caeruleus (Bondareff et al. 1981) sowie der Hippokampus mit angrenzendem entorhinalem Kortex, welche besonders früh und stark betroffen sind (West et al. 2004; Wirths et al. 
2004). Die Korrelation zwischen verminderter Neuronenzahl und verkleinertem Hirnareal lässt vermuten, dass die Schrumpfung des Hirnareals Folge des Neuronenverlustes ist (Kril et al. 2004). Andererseits zeigen Regressionsanalysen, dass der Neuronenuntergang weniger mit dem klinischen Schweregrad der Erkrankung einhergeht als mit dem Verlust von Synapsen (Terry et al. 1991).

\subsubsection{Risikofaktoren und Prädispositionen der Alzheimer-Erkrankung}

Das Alter ist der wichtigste Risikofaktor für die Entwicklung der Alzheimer-Demenz. Daneben gibt es noch weitere Faktoren und Prädispositionen, die mit einem erhöhten Risiko für die Erkrankung verbunden sind.

\subsubsection{Hereditäre Faktoren}

Autosomal dominante Erbgänge für die Alzheimer-Erkrankung sind in 5-10\% der Fälle zu finden. Bekannt sind drei verschiedene Mutationen: das Presenilin-1-Gen (PS1) auf Chromosom 14, das Presenilin-2-Gen (PS2) auf Chromosom 1 und das Amyloid-Vorläufer-Protein (APP) auf Chromosom 21 (Masuhr und Neumann 2007).

Mutationen im APP-Gen sind die zuerst gefundene Ursache für hereditäre Formen der AD (Goate et al. 1991), die aber sehr selten ist. Bislang sind 17 verschiedene Mutationen für das APP-Gen bekannt (Rogaeva 2002). Familienmitglieder, in deren Familien die Alzheimer-Demenz durch Vererbung mutierter APP-Gene auftritt, erkranken meist vor dem 65. Lebensjahr (Selkoe 2001).

Die Mutationen im APP-Gen liegen nahe den Sekretase-Schnittstellen. So ist die London-Mutation $\mathrm{APP}_{\mathrm{V} 717 \mathrm{~F}}$ an der $\gamma$-Sekretase-Schnittstelle lokalisiert. An der Basenposition 717 ist Valin gegen Phenylalanin, Glycin oder Isoleucin ausgetauscht (Chartier-Harlin et al. 1991; Goate et al. 1991; Mullan et al. 1993). Diese Mutation geht einher mit einem erhöhten $A \beta-42 / A \beta-40$ Quotient und auch zu insgesamt erhöhten Mengen von A $\beta$ (Suzuki et al. 1994).

Die schwedische Mutation $\mathrm{APP}_{\mathrm{K} 670 \mathrm{~N}, \mathrm{M} 671 \mathrm{~L}}$ ist eine Doppelmutation, die in der Nähe der $\beta$-Sekretase-Schnittstelle liegt. An Position 670 und 671 sind die AS Lysin und Methionin gegen Asparagin und Leucin ausgetauscht (Mullan et al. 1992), was zu einer erhöhten Menge an A $\beta$ führt (Haass et al. 1995).

Eine andere Form für APP-assoziierte AD wurde bei Down-Syndrom-Patienten beobachtet. Aufgrund der erhöhten Dosis von Chromosom 21 kommt es zur vermehrten Bildung von A $\beta$-Peptiden der Isoformen mit 40, 42 und 43 Aminosäuren 
(AS) (Tokuda et al. 1997), wobei die 42- und 43-AS-Variante als besonders neurotoxisch gelten (Yankner et al. 1990; Lorenzo und Yankner 1994).

Mutationen der Gene für Präsenilin 1 und 2 führen auch zu erhöhten Mengen von A $\beta$ 42 und somit zu gesteigerter A $\beta$-Aggregation (Borchelt et al. 1996). Des Weiteren ist Präsenilin 1 von Bedeutung für die Bildung des $\gamma$-Sekretase-Komplexes, der für die APP-Prozessierung notwendig ist (De Strooper 2003).

Fälle von familiärem Alzheimer, welche keine der genannten Mutationen als Ursache haben, lassen vermuten, dass es noch weitere Gene gibt, die mit der AlzheimerErkrankung assoziiert sind. Z.B. wird vermutet, dass das Alpha-2-Makroglobulin von Bedeutung ist (Blacker et al. 1998).

\subsubsection{Das Apolipoprotein E4}

Für das Apolipoprotein-E-Gen auf Chromosom 19q (ApoE) gibt es drei Allele: $\varepsilon 2$, $\varepsilon 3$ und $\varepsilon 4$. Untersuchungen zeigten, dass das $\varepsilon 4$-Allel bei Alzheimer-Patienten häufiger vorkommt als die anderen Allele für ApoE (Saunders et al. 1993; Strittmatter et al. 1993). Zusätzlich zeigte sich eine Dosisabhängigkeit. Patienten, die homozygot für $\varepsilon 4$ sind, haben ein höheres Risiko, an $\mathrm{AD}$ zu erkranken, als Träger, die nur ein $\varepsilon 4-A l l e l$ tragen. Des Weiteren erkranken Patienten mit höherer Gendosis statistisch gesehen früher (Corder et al. 1993). Da aber nicht jeder homozygote Träger von $\varepsilon 4$ obligat an AD erkrankt, gilt das ApoE4 als Risikofaktor für die late-onset bzw. sporadische Variante der AD und nicht als direkte Ursache (Selkoe 2001). Für das ع2-Allel gibt es Hinweise, protektiven Charakter zu besitzen (Corder et al. 1994). Der Zusammenhang von ApoE4 und der Alzheimer-Demenz ist noch nicht endgültig geklärt. Wahrscheinlich beeinflusst das ApoE den A $\beta$-Peptid-Stoffwechsel.

\subsubsection{Kopftraumata}

Fallkontrollstudien zeigten, dass Menschen mit Kopfverletzungen ein signifikant erhöhtes Risiko haben, an der Alzheimer-Demenz zu erkranken (French et al. 1985; Mortimer et al. 1985; Graves et al. 1990). Auf noch unbekannte Weise führen die Kopftraumen zu AD-typischen Ablagerungen von A $\beta$ (McKenzie et al. 1994; Roberts et al. 1994).

\subsubsection{Bildungsniveau}

Manche Studien zeigten, dass eine geringere Bildung mit einem höheren Risiko für Demenzerkrankungen assoziiert ist (Mortimer et al. 2003). Andere zeigten, dass ein niedriges Bildungsniveau für die $\mathrm{AD}$ ein Risikofaktor ist, aber nicht generell für 
Demenzen (Gatz et al. 2001). Eventuell haben Patienten, welche mehr Bildung erfahren haben, eine kognitive Reserve, die vor der Alzheimer-Demenz schützt oder zumindest das Erkrankungsalter hinauszögert (Cummings et al. 1998).

\subsubsection{Geschlecht als Risikofaktor}

Epidemiologische Untersuchungen zeigten, dass die Prävalenz- und Inzidenzraten, bezogen auf das Geschlecht, unterschiedlich sind. So haben Frauen ein höheres Risiko, an der Alzheimer-Demenz zu erkranken (Jorm und Jolley 1998; Andersen et al. 1999). Der Grund dafür ist noch nicht geklärt, Untersuchungen deuten aber darauf hin, dass die Geschlechtshormone eine wichtige Rolle spielen.

Frauen, die aufgrund einer beidseitigen Ovarektomie eine Hormonersatztherapie (HET) erhalten, verbessern ihre kognitiven Leistungen im Vergleich zu Frauen, die ein Placebo erhalten haben (Phillips und Sherwin 1992). Ein weiterer Hinweis für den postmenopausalen Östrogenmangel als Risikofaktor für die Manifestation einer AD ist, dass gezeigt wurde, dass eine postmenopausale HET das Risiko für die Entstehung der Erkrankung senkt (Henderson et al. 1994; Mortel und Meyer 1995) bzw. dass Frauen, die an AD erkrankt sind, niedrigere Östradiolspiegel aufweisen (Manly et al. 2000). Andere Studien kamen aber zu dem Ergebnis, dass die HET keinen (BarrettConnor und Kritz-Silverstein 1993) oder einen negativen (Rapp et al. 2003) Effekt auf die Kognition haben. Des Weiteren werden auch die hypothalamischen Hormone LH und FSH als geschlechtsspezifische Risikofaktoren diskutiert.

Auch mikropathologische Untersuchungen zeigen Unterschiede bezüglich des Geschlechts. Weibliche Gehirne weisen die für AD typischen pathologischen Veränderungen in höherem Maße auf als männliche (Kraszpulski et al. 2001; Barnes et al. 2005).

\subsubsection{Protektive Faktoren}

Neben der bereits erwähnten HET, die in manchen Quellen als protektiv, bezüglich der $\mathrm{AD}$, angesehen wird, gibt es noch andere Faktoren, die als Schutzfaktor diskutiert werden. Dazu gehören die NSAIDs (nonsteroid anti inflammatory drugs), bei denen aufgefallen ist, dass das Risiko für Patienten, deren rheumatische Erkrankung mit NSAIDs behandelt wurde, niedriger ist, an AD zu erkranken (Jenkinson et al. 1989). Auch McGeer et al. kommt mit einer Metaanalyse von 17 Studien zu einem ähnlichen Ergebnis, nämlich dass NSAIDs einen potektiven Faktor gegen die Entwicklung einer AD darstellen (McGeer PL et al. 1996). Eine mögliche Erklärung dafür gibt derselbe 
Autor in einer anderen Quelle, in der der inflammatorische Prozess an den Plaques mit Mikroglia, Komplement und Akute-Phase-Proteinen untersucht wird, die eine antiinflammatorische Therapie sinnvoll erscheinen lässt (McGeer PL und McGeer EG 1996).

\subsubsection{Pathomechanismen der Alzheimer-Erkrankung}

\subsubsection{Das Amyloid-Precursor-Protein APP}

Das Amyloid-Vorläufer-Protein (APP) gehört zur Familie der Amyloid-Vorläuferähnlichen Proteine. Der genetische Code des APP liegt auf dem langen Arm des Chromosom 21 (Kandel et al. 2000). Das APP kommt in verschiedenen Isoformen mit verschieden vielen Aminosäuren (AS), die alle den A $\beta$-Abschnitt beinhalten, vor: 695 AS (Kang et al. 1987), 717 AS (Chartier-Harlin et al. 1991), 751 AS und 770 AS (Tanaka et al. 1988). Nachgewiesen wurde das APP in Dendriten, Axonen und Zellkörpern von Neuronen, wobei die Funktion noch unklar ist. Als transmembranöses Protein mit einer transmembranen Domäne hat es drei Abschnitte: einen kurzen intrazytoplasmatischen, einen transmembranösen und einen langen extrazellulären. Der $A \beta$-Abschnitt ist eingebettet in den extrazellulären und den transmembranösen Abschnitt des APP (Kandel et al. 2000). 


\subsubsection{Die APP-Verarbeitung}

Das membrangebundene APP hat drei Schnittstellen für drei Sekretasen $(\alpha, \beta, \gamma)$, die entscheidend sind für die posttranslationale Prozessierung, bei welcher zwei verschiedene Pfade möglich sind. Wenn das Protein von der $\alpha$-Sekretase proteolysiert

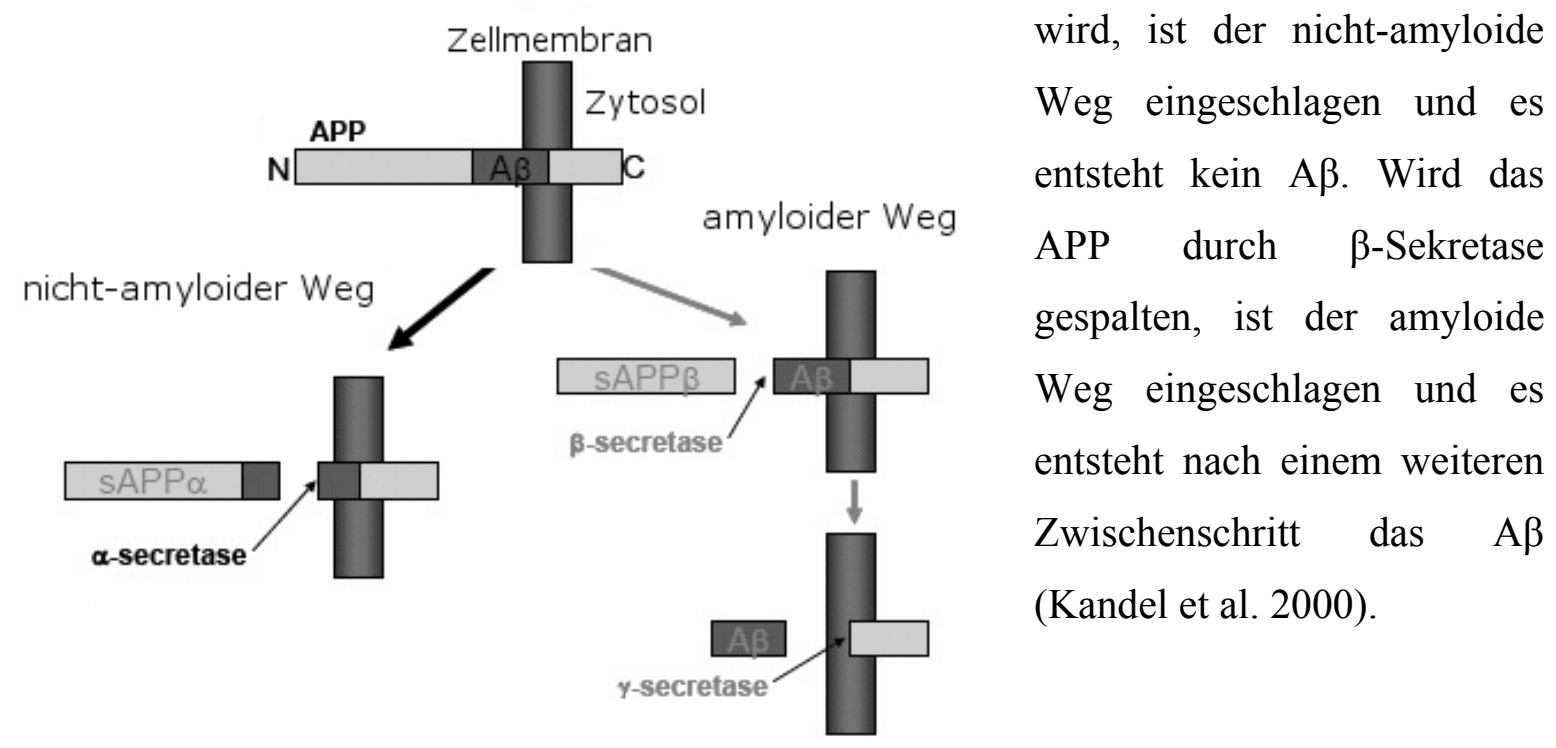

Abbildung 5 Zwei verschiedene Wege der posttranslationalen Prozessierung des APP, modifiziert nach www.fbs.leeds.ac.uk (2009)

Hauptsächlich läuft die APP-Prozessierung über den nicht-amyloiden Weg. Die $\alpha$ Sekretase schneidet das APP innerhalb der A $\beta$-Sequenz, wobei das lösliche sAPP $\alpha$ und ein membrangebundener Rest entstehen. Die genauere Untersuchung der $\alpha$ Sekretase zeigt, dass das Enzym dem TACE (tumor necrosis factor $\alpha$ converting enzyme), einem Mitglied der ADAM-Familie (a disintegrin and metalloproteasefamily) ähnlich ist (Buxbaum et al. 1998; Lammich et al. 1999).

Die Prozessierung des APP entlang des amyloiden Weges durch die $\beta$ - und $\gamma$ Sekretase führt zur Bildung von A $\beta$-Peptiden, die, wie bereits beschrieben, Bestandteil der Plaques sind.

\subsubsection{Die Hypothese der $\beta$-Amyloid-Kaskade}

Die $\beta$-Amyloid-Kaskaden-Hypothese wurde 1991 von Hardy und Allsop formuliert und beschreibt eine mögliche Abfolge der Pathogenese der Alzheimer-Demenz. Demnach führt eine gestörte APP-Prozessierung zur Synthese und Akkumulation des $\mathrm{A} \beta \mathrm{zu}$ extrazellulären Plaques. Die Plaques führen zum Verlust von Neuronen und Synapsen, also einer Atrophie von Hirngewebe. Dies führt zu dem klinischen Korrelat Demenz (Hardy und Allsop 1991). 


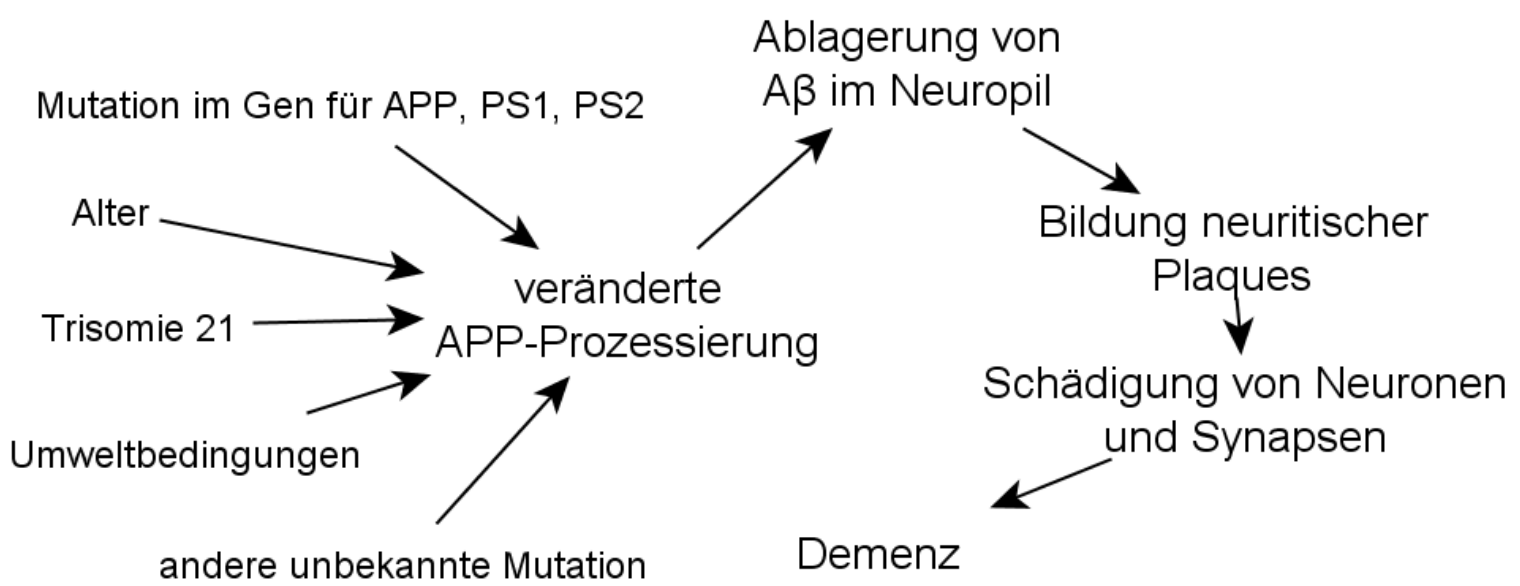

Abbildung 6 Die $\beta$-Amyloid-Kaskaden-Hypothese nach Hardy und Allsop (Hardy und Allsop 1991, S. 387)

Andere Ergebnisse passen jedoch nicht zu dieser Hypothese. Der Plaqueload korreliert nicht mit dem neuropathologischen Status bzw. Braak-Level der Betroffenen im Gegensatz zu den neurofibrillären Tangles (Arnold et al. 1991; Braak H und Braak E 1991), welche auch gut mit dem klinischen Erscheinungsbild korrelieren (Morrison und Hof 1997; Nagy et al. 1999). Die seit kurzer Zeit beforschte Neurotoxizität der intrazellulären $A \beta$-Ablagerungen lässt $\mathrm{zu}$, eine modifizierte $\beta$-Amyloid-KaskadenHypothese zu formulieren: Demnach verursacht das intrazellulär anfallende $A \beta$ die für die AD typischen, neuromikropathologischen Veränderungen. Zur Gehirnatrophie durch Verlust von Synapsen und Neuronen kommt eine gesteigerte A $\beta$-Sekretion, die als Folge die Bildung von extrazellulären Plaques hat (Wirths et al. 2004).

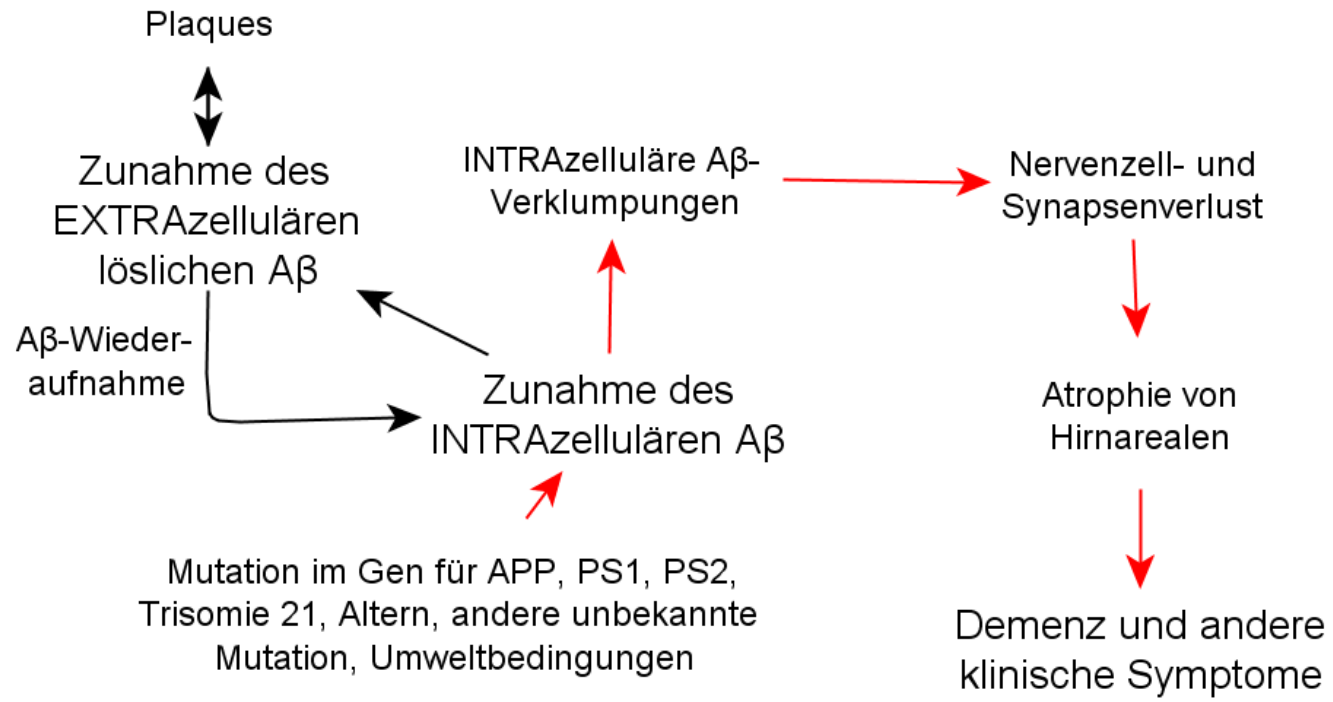

Abbildung 7 Die modifizierte $\beta$-Amyloid-Kaskaden-Hypothese nach Wirths et al. (Wirths et al. 2004, S. 517) 


\subsubsection{Mausmodelle in der Alzheimer-Forschung}

Die Möglichkeit, humane Gene, die im Zusammenhang mit der AD stehen, in das Erbgut von Mäusen einzubringen, stellt eine Grundlage dar, die bereits bekannten Mutationen (für APP, PS1 und PS2) im Einzelnen und im Vergleich zum Wildtyp zu untersuchen. Um für die Alzheimer-Forschung relevant zu sein, ist es wichtig, dass die Expression der eingebrachten Gene zu den AD-typischen Pathologien führt: $A \beta$ Ablagerungen, neurofibrilläre Tangles, Neuronen- und Synapsenverlust, Verhaltensänderung. Mit der Zeit wurden verschiedene Mausmodelle entwickelt, welche zunehmend diese Kriterien erfüllen (Kandel et al. 2000).

Die in dieser Arbeit untersuchte transgene Maus mit der Bezeichnung APP ${ }^{\mathrm{SL}} \mathrm{PS} 1 \mathrm{KI}$ wurde 2004 von Casas et al. vorgestellt. Sie hat die knocked-in Mutationen M233T/L235P im PS1-Gen und zeigt eine Überexpression von humanem mutierten APP. Das eingebrachte APP751 beinhaltet die schwedische und londonsche Mutation (siehe hereditäre Faktoren). Das synthetisierte $A \beta$ entspricht zum größten Teil der $\mathrm{A} \beta_{42}$-Isoform. Im Alter von zehn Monaten ist die Neuronenzahl in der Pyramidenzellschicht in der Hippokampusregion CA1/2 um mehr als die Hälfte vermindert. Dieser Neuronenverlust korreliert mit intraneuronalem A $\beta$ sowie thioflavin-S-positiven Ablagerungen in den Neuronen, aber nicht mit den extrazellulären A $\beta$-Ablagerungen. Der Neuronenverlust ist bereits nach sechs Monaten gut zu erfassen. Diesem folgt eine reaktive Astrogliose (Casas et al. 2004; Christensen et al. 2008b).

\subsection{Zielsetzung}

In der vorliegenden Arbeit wurde der Neuronenverlust im Thalamus von $\mathrm{APP}^{\mathrm{SL}} \mathrm{PS} 1 \mathrm{KI}-\mathrm{Mäusen}$ stereologisch untersucht, da in dieser Hirnregion nur Plaques vorkommen und kein intrazelluläres $\mathrm{A} \beta$. Zeitgleich, im Rahmen einer anderen Promotionsarbeit (erarbeitet von Sophie Kraus), wurde der Neuronenverlust derselben Mäuse im Kortex untersucht, wo neben Plaques auch intrazelluläre A $\beta$-Ablagerungen vorkommen. Der Vergleich der Daten aus beiden Regionen lässt sehen, ob das Neuronenüberleben besser in einer Umgebung mit Plaques und intraneuronalem A $\beta$ (Kortex) ist oder in einer Region mit nur Plaques (Thalamus). Die Ergebnisse werden also einen Hinweis darauf geben, ob Plaques oder eher das intrazelluläre $A \beta$ als Auslöser für den Neuronenuntergang in Betracht kommen. 


\section{Material und Methoden}

\subsection{Transgene Maus}

Zur stereologischen Untersuchung wurden die Gehirnschnitte von insgesamt 39 Mäusen verwendet. zehn Mäuse davon waren im Alter von zwei Monaten, 12 Mäuse im Alter von sechs Monaten und 17 Mäuse im Alter von 12 Monaten (siehe Tabelle 1). Die Mäuse des Alzheimer-Modells APP/PS1KI wurden in jeder Altergruppe mit Kontroll-Mäusen des Mausmodells PS1KI verglichen.

Die Mäuse mit dem doppelt-transgenen Status APP/PS1KI entwickeln die Alzheimertypischen neuropathologischen Veränderungen, wie Amyloid-Plaques und intraneuronales $A \beta$ in hippokampalen und kortikalen Bereichen schon im Alter von zwei Monaten. Des Weiteren ist bei diesen Mäusen ein signifikanter Neuronenverlust in der Hippokampusregion CA1/2 feststellbar, der in anderen AlzheimerMausmodellen bis jetzt nicht erzielt werden konnte. Die Mäuse haben im Presenilin-1 Gen eine M233T/L235P knock-in-Doppelmutation. Zusätzlich überexprimieren sie mutiertes humanes APP (siehe Abschnitt 1.4.7) (Casas et al. 2004).

Alle Mäuse waren weiblich. Durch PCR der DNA, die durch Biopsie der Ohren gewonnen wurde, ermittelte man den transgenen Status der Mäuse. Alle Tiere wurden gemäß den deutschen Richtlinien für Tierschutz behandelt.

\begin{tabular}{|c|c|c|c|}
\hline & 2 Monate & 6 Monate & $\begin{array}{c}12 \\
\text { Monate }\end{array}$ \\
\hline $\begin{array}{c}\text { APP/PS1 } \\
\text { KI }\end{array}$ & 5 Mäuse & 6 Mäuse & 9 Mäuse \\
\hline PS1K & 5 Mäuse & 6 Mäuse & 8 Mäuse \\
\hline
\end{tabular}

Tabelle 1: Übersicht der untersuchten Mäuse

\subsection{Gewinnung und Aufbereitung des Hirngewebes}

Zuerst wurden die Mäuse mit einem Narkotikum betäubt. Das Gehirn wurde zunächst mit ca. 5 bis $10 \mathrm{ml}$ eiskaltem 0,01M PBS perfundiert indem die linke Herzkammer mit 
einer Kanüle punktiert wurde. Zur Entlastung des Kreislaufs wurde der rechte Vorhof eröffnet. Zur Fixation wurde anschließend die gleiche Menge 4\%iges Paraformaldehyd eingeleitet. Der Kopf wurde auf Höhe der atlanto-axialen Verbindung abgetrennt und von Anterior eröffnet. Die Hemisphären wurden entlang der Medianlinie voneinander getrennt. Die linken Hälften wurden in $4^{\circ} \mathrm{C}$ temperierten Paraformaldehyd für zwei Stunden inkubiert. Danach wurden sie in $30 \%$ ige Saccharoselösung versetzt, in der sie bis zum nächsten Tag bei $4^{\circ} \mathrm{C}$ zum Gefrierschutz inkubiert wurden. Zuletzt wurden die linken Hirnhälften auf Trockeneis tiefgefroren und bis zur weiteren Verwendung bei $-80^{\circ} \mathrm{C}$ eingelagert. Die rechten Hemisphären wurden nach Entnahme direkt auf Trockeneis eingefroren und bei $-80^{\circ} \mathrm{C}$ bis zur weiteren Verwendung eingelagert.

\subsection{Herstellung der Hirnschnitte}

Zunächst wurden die Maushemisphären bei $-20^{\circ} \mathrm{C}$ mittels Gewebekleber auf einem Schneideblock fixiert. Dazu wurde der Kleber in Schichten um das Hirngewebe gegossen und gewartet, bis die jeweilige Schicht ausgehärtet war. Die linken Hemisphären wurden in zehn Serien mit jeweils $30 \mu \mathrm{m}$ Abstand in der Koronarebene mit einem Kryostat geschnitten. Jede Serie wurde in separaten Gefäßen bis zur weiteren Verwendung bei $-80^{\circ} \mathrm{C}$ eingelagert.

Kryostat: MICROM HM550

Gewebekleber: Tissue-Tek ${ }^{\circledR}$ O.C.T. ${ }^{\text {TM }}$ Compound, SAKURA Finetek Europe B.V. Gefäße: Straight-Side Wide-Mouth Jar PC, Size 15ml, Nalge Nunc International

\subsection{Cresyl-Violett-Färbung}

Alle Schnitte einer Serie aus einem Gefäß wurden mit der free-floating-Methode auf elektrostatisch geladene Objektträger gebracht. Dazu wurden die Schnitte in eiskaltem PBS suspendiert und mit einem sehr feinen Pinsel auf den Objektträger gezogen. Über Nacht erfolgte eine Trocknung an der offenen Luft bei Raumtemperatur.

Objektträger: Superfrost ${ }^{\circledR}$ Plus, 25 x 75x 1,0 mm, Menzel GmbH \& Co KG, Braunschweig 
Die Cresyl-Violett-Färbung wurde anhand folgender Färbeanleitung durchgeführt:

Färbeanleitung:

1) Puffer:

1A (Stocklösung): 1M Natriumacetat (136,08g Na-Acetat-Trihydrat in 1Liter Milli-Q)

1B (Arbeitslösung): $40 \mathrm{ml} 1 \mathrm{M}$ Natriumacetat (1A) + 9,6 ml Essigsäure konz., auffüllen auf 1 Liter mit Milli-Q.

2) Färbelösung (am Vortag herstellen):

$0,1 \mathrm{~g}$ Cresylviolett in 1 Liter der Lösung 1B lösen

30 min rühren,

über Nacht stehen lassen,

kurz vor Gebrauch filtern.

3) Entfettungslösung:

3A (Stocklösung): 2\%ige Triton X-100 (980 ml Milli-Q + $20 \mathrm{ml}$ Triton X-100), ungefähr $1 \mathrm{~h}$ rühren (lange haltbar)

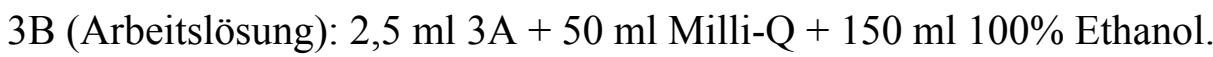

Färbeprotokoll:

$1.2 \times 10 \mathrm{~min}$ in $1 \mathrm{~B}$ (2 verschiedene Küvetten)

2. $20 \mathrm{~min}$ in $3 \mathrm{~B}$

$3.2 \times 10 \mathrm{~min}$ in $1 \mathrm{~B}$ (2 verschiedene Küvetten)

$4.2 \times 8$ min in 2 ( 2 verschiedene Küvetten)

$5.3 \times 1 \mathrm{~min}$ in $1 \mathrm{~B}$ (3 verschiedene Küvetten)

6. $3 \mathrm{~min}$ in $100 \%$ Ethanol

7. 1 x $10 \mathrm{~min}$ in Isopropanol (=2-Propanol)

$8.2 \times 5 \mathrm{~min}$ in Xylo

9. mit Corbit-Balsam einschließen und über Nacht trocknen lassen.

\subsection{Stereologie}

Zur Quantifizierung der Neurone im Thalamus der Mausgehirne wurde die „Design Based Stereology“ verwendet. Mit dieser statistischen Methode ist es möglich 
verschiedene Parameter, wie z.B. Volumen oder Zellzahl, eines dreidimensionalen Gewebes anhand von zweidimensionalen Schnitten zu ermitteln. Ein Vorteil dieser Methode ist, dass die Ergebnisse erwartungstreu (,unbiased“) sind.

Die stereologische Untersuchung wurde mit dem Programm „Stereo Investigator 7“ (MicroBrightfield) im Modus „Optical Fractionator“ (Einstellungen siehe Tabelle 2) und einem BX51 Mikroskop (Olympus) durchgeführt.

Die Voraussetzung einer stereologischen Untersuchung ist das sogenannte „Systematic Random Sampling“. Dazu wird eine der zehn 30 $\mu \mathrm{m}$ Serien zufällig gewählt. Das Systematische daran ist der Abstand der Schnitte voneinander. In diesem Fall sind es $300 \mu \mathrm{m}$ zwischen den Stichproben, da nur jeder zehnte der $30 \mu \mathrm{m}$ Schnitte untersucht wurde.

\begin{tabular}{|l|r|}
\hline Counting Frame Area $(\mathrm{XY})\left(\mu \mathrm{m}^{2}\right)$ & 1600 \\
\hline Disector Height $(\mathrm{Z})(\mu \mathrm{m})$ & 6 \\
\hline Disector Volume $(\mathrm{XYZ})\left(\mu \mathrm{m}^{3}\right)$ & 9600 \\
\hline Counting Frame Width $(\mathrm{X})(\mu \mathrm{m})$ & 40 \\
\hline Counting Frame Height $(\mathrm{Y})(\mu \mathrm{m})$ & 260 \\
\hline Sampling Grid $(\mathrm{X})(\mu \mathrm{m})$ & 250 \\
\hline Sampling Grid $(\mathrm{Y})(\mu \mathrm{m})$ & 65000 \\
\hline Sampling Grid Area $(\mathrm{XY})\left(\mu \mathrm{m}^{2}\right)$ & 30 \\
\hline Section Thickness $(\mu \mathrm{m})$ & 10 \\
\hline Section Periodicity & on \\
\hline Focus Method & manual focus \\
\hline Refocus to top of section on each grid site & $15^{\text {th }}$ grid site \\
\hline Measure section thickness at every & 0,00 \\
\hline Grid Rotation (degrees) & 2 \\
\hline Distance from section top to 3D counting frame $(\mu \mathrm{m})$ & \\
\hline
\end{tabular}

Tabelle 2: Gewählte Parameter im Stereo Investigator 7

Zur Bestimmung der Neuronenzahl werden dreidimensionale Zählrahmen („Counting Frames") auf die Schnitte angewendet. Die Zählrahmen haben entsprechend ihrer Dreidimensionalität drei Achsen: X, Y und Z. 
Von entscheidender Bedeutung ist die Einhaltung von bestimmten Zählregeln („Counting Rules“), welche eine fehlerfreie Zellzahlbestimmung garantieren.

Zählregeln:

- Es dürfen nur Objekte gezählt werden, die sich innerhalb des dreidimensionalen Zählrahmens, beim Durchfokussieren entlang der Z-Achse, scharf stellen lassen. Objekte, deren Fokus außerhalb oder an der oberen Grenze des Zählrahmens liegt, dürfen nicht gezählt werden. Stellt sich eine Zelle innerhalb des Rahmens scharf und erstreckt sich über die untere Grenze hinaus, wird sie mitgezählt.

- Jeder Zählrahmen hat sechs Seiten, wovon drei aneinandergrenzende als Ausschlussgrenzen angesehen werden. Die anderen drei Seiten sind keine Grenzschicht. Das heißt, dass Objekte die nur teilweise innerhalb des Rahmens liegen, nur dann gezählt werden dürfen, wenn sie keine der Ausschlussgrenzen berühren.

Zur Quantifizierung der Neurone im Thalamus erfolgte die genaue Orientierung anhand eines Bildatlas der Neuroanatomie der Maus. Gezählt wurde von Bregma -0,94 bis -2,54 (Paxinos und Franklin 2001).

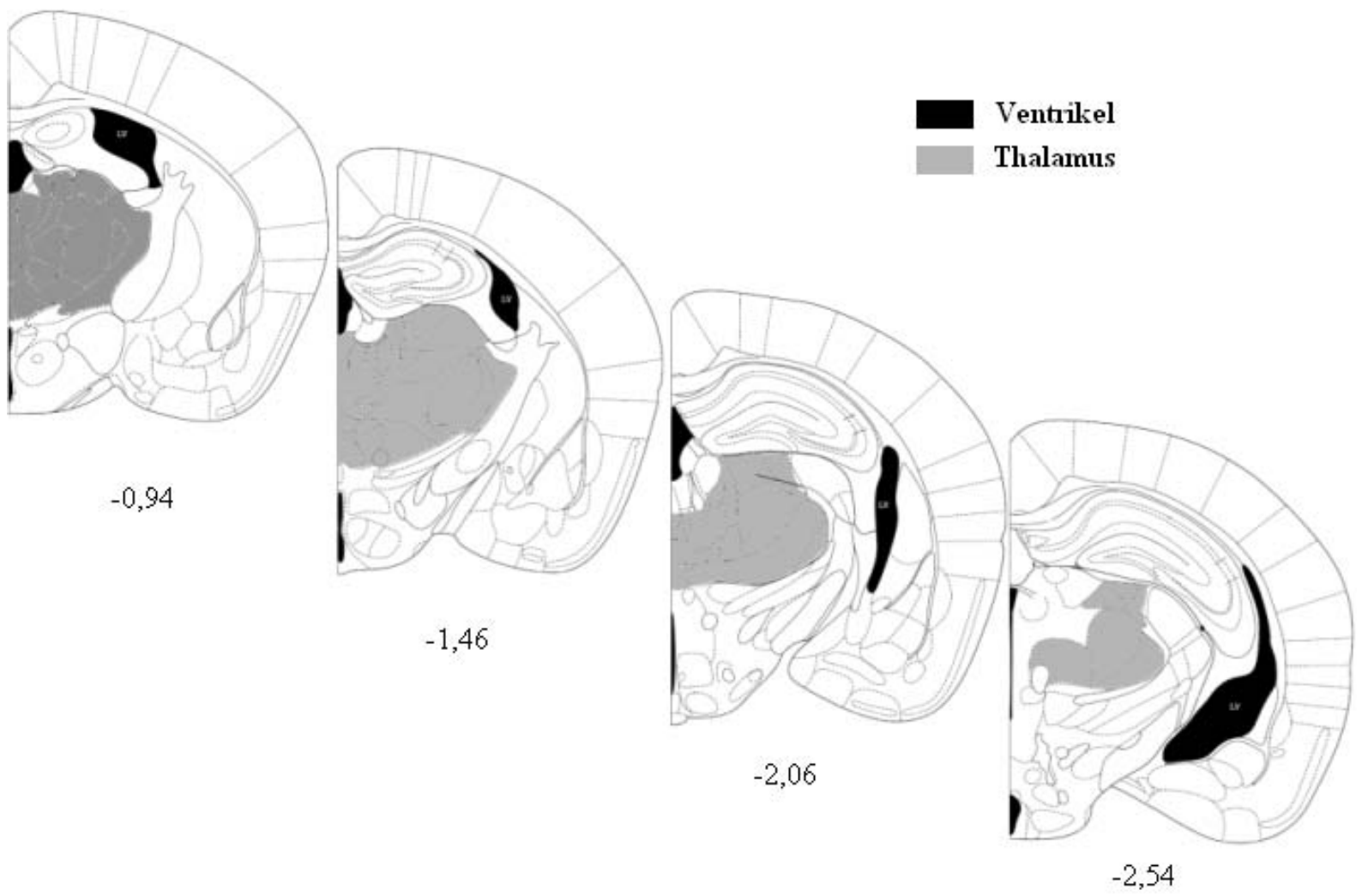

Abbildung 8 Schematische Darstellung des Thalamus von Bregma -0,94 bis -2,54, erstellt mit „The mouse brain in stereotaxic coordinates“ (Paxinos und Franklin 2001) 
Die Abschätzung und Berechnung der Neuronenzahl erfolgte gemäß den Prinzipien der Stereologie (West et al. 1991; West 2002; Schmitz und Hof 2005). Vor dem Zählen wurde der Genotyp der Mäuse von einer anderen Person verblendet.

\subsection{Immunhistochemische Färbung der Paraffinschnitte}

Die Mäuse wurden transkardial, durch Punktion des linken Ventrikels mit 4\% PFA in PBS perfundiert. Die Gehirne wurden vorsichtig entnommen und in der gleichen Lösung aufbewahrt, bis sie in Paraffin eingelassen wurden. Die immunhistochemische Aufbereitung der $4 \mu \mathrm{m}$ Parafinschnitte erfolgte wie bereits beschrieben (Wirths et al. 2002). Die Schnitte wurden in Xylen deparaffinisiert und in einer Reihe von Ethanollösungen mit aufsteigender Konzentration rehydriert. Nach Behandlung mit 0,3\%igem $\mathrm{H}_{2} \mathrm{O}_{2}$, zur Hemmung der endogenen Peroxidase, wurden die Antigenstrukturen durch Kochen in 0.01 M Zitratpuffer pH 6,0 und anschließender dreiminütiger Inkubation in $88 \%$ iger Ameisensäure wieder reagibel gemacht. Unspezifische Bindungsstellen wurden mit Magermilch und fetalem Kälberserum in PBS blockiert. Zur Färbung wurden folgende Antikörper verwendet: 23850 gegen humanes APP (zur Verfügung gestellt von Gerd Multhaupt), ein N-terminaler A $\beta$ Antikörper ( $\mathrm{Ab}[\mathrm{N}], \mathrm{IBL}$, Hamburg, Germany), ein Antikörper zur Auffindung des Aspartat an Position 1 (N1D) und ein Antikörper gegen Pyroglutamat an Position 3 (N3pE; beide Antikörper wurden zur Verfügung gestellt von Takaomi C. Saido), G210 gegen A $\beta 40$ (The Genetics Company) und 4G8 (Covance). Die primären Antikörper wurden über Nacht in einem feuchten Inkubator bei Raumtemperatur gelagert. Die sekundären biotinylierten Antikörper (DAKO, Glostrup, Dänemark) wurden nachfolgend appliziert. Die Färbung wurde sichtbar gemacht mit der ABCMethode mit Hilfe des „Vectastain-Kit“(Vector Laboratories, Burlin-game, USA) und Diaminobenzidin (DAB) als Chromogen, welches eine rotbraune Farbe gibt. Zusätzlich erfolgte eine kontrastgebende Färbung mit Hämatoxylin. Alle gefärbten PS1K1 Kontrollmäuse waren durchgehend negativ für APP and A $\beta$.

\subsection{A $\beta$-load-Bestimmung}

Von jedem Tier wurden fünf Paraffinschnitte, die mindestens $25 \mu \mathrm{m}$ voneinander entfernt sind, gleichzeitig mit DAB als Chromogen und einer niedrigen Konzentration 4G8-Antikörper (1:10.000), um Kreuzreaktionen mit APP zu minimalisieren, gefärbt.

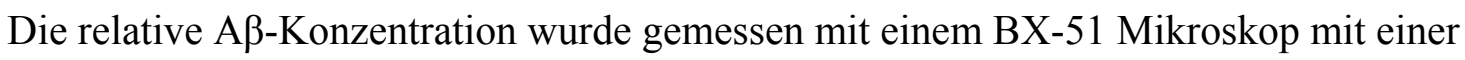


DP-50 Kamera (beides von Olympus) und der Software „ImageJ“ (NIH, USA). Die Bilder wurden systematisch mit zehnfacher Vergrößerung aufgenommen. Anschließend wurden die Bilder mit „ImageJ“ in 8-Bit Schwarz-Weiß-Bilder umgewandelt. Für die Umwandlung wurde durchgehend der gleiche Grenzwert benutzt. Es wurden folgende Parameter erhoben:

- Fläche, die von DAB angefärbt ist, in Prozent

- Anzahl von DAB angefärbten „Grains“ pro $\mathrm{mm}^{2}$

- Durchschnittliche Größe der einzelnen DAB angefärbten „Grains“.

Da im Thalamus kein intraneuronales $A \beta$ vorhanden ist, entsprechen die „Grains“ den Plaques. Hingegen entsprechen die „Grains“ im Frontalkortex auch den intraneuronalen Ablagerungen.

\subsection{Statistik}

Die Analyse der stereologisch gewonnenen Daten erfolgte mit einer zweifaktoriellen ANOVA-Varianzanalyse und anschließender Bonferroni-Korrektur. Die A $\beta$ Pathologien wurden mit einer einfaktoriellen ANOVA-Varianzanalyse gefolgt von TTests analysiert. Alle aufgeführten Zahlen sind Mittelwerte \pm Standardabweichung. Die statistische Auswertung wurde mit dem Programm „GraphPad Prism“ Version 4.03 für Windows (GraphPad Software, San Diego, CA, USA) durchgeführt. 


\section{Ergebnisse}

Die Zielsetzung der vorliegenden Arbeit besteht darin, die Thalamusregion in Bezug auf Neuronenzahl, Volumen und Ablagerungen zu untersuchen. Die Ergebnisse dieser Analyse erlangen ihre volle Bedeutung erst im Kontext der Ergebnisse einer parallel erstellten Promotionsarbeit von Sophie Kraus, bei welcher der Frontalkortex derselben Mäuse untersuchte wurde. Aus diesem Grund werden im nachfolgenden Abschnitt die Ergebnisse des Thalamus und auch des Frontalkortex vorgestellt.

Des Weiteren werden auch die Ergebnisse einer späteren Messung der A $\beta$ Ablagerungen gezeigt, die auch zwölf Monate alte Mäuse mit einbezieht.

\subsection{A $\beta$-Ablagerungen}

\subsubsection{Plaqueload (Fläche, die von $A \beta$ bedeckt ist)}

Die Plaque-Bedeckung, die mit Hilfe des 4G8-Antikörpers (gegen A $\beta$-Peptid)

\section{$\%$ plaque load}

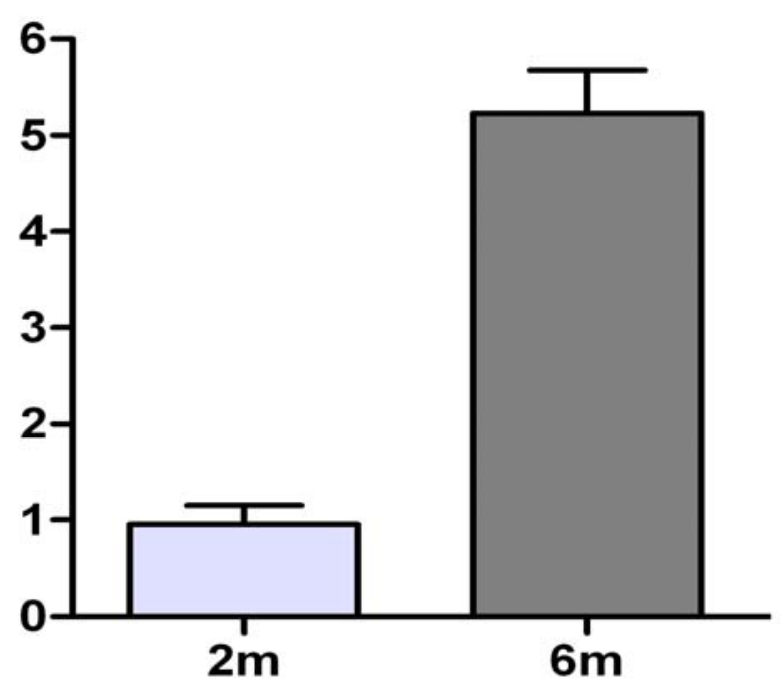

angefärbt wurde und mit einer Dichtemessung durch Software quantifiziert wurde, betrug bei den zwei Monate alten Tieren etwa ein Prozent. Die sechs Monate alten Tiere weisen einen Plaqueload von etwa fünf Prozent auf. Das ist eine Verfünffachung in vier Lebensmonaten.

Abbildung 9 Plaqueload im Thalamus in Prozent Fläche der Gesamtfläche bei zwei und sechs Monate alten Mäusen.

Nachfolgend wurden in einem neuen Testansatz auch zwölf Monate alte Mäuse einbezogen. Im Thalamus zeigt sich ein Plaqueload von 1,5 \% der Gesamtfläche im Alter von zwei Monaten. Die sechs Monate alten Tiere weisen einen Plaqueload von 8,5 \%. Mit zwölf Monaten beträgt die bedeckte Fläche 13,9 \%. Der Vergleich der 
ersten zwei Altersgruppen zeigt einen signifikanten Unterschied mit $p<0,05$ und auch der Unterschied der Altersgruppen sechs und zwölf Monate ist mit $\mathrm{p}<0,01$ signifikant.

Die parallel dazu erhobenen Daten im Frontalkortex zeigen eine anfängliche Zunahme der Plaque-Bedeckung von 4,7\% bei zwei Monaten auf 12,1\% bei sechs Monaten. Der Unterschied ist mit $p<0,001$ signifikant. Eine weitere Zunahme bis zum zwölften Lebensmonat erfolgt nicht.

Frontal Cortex

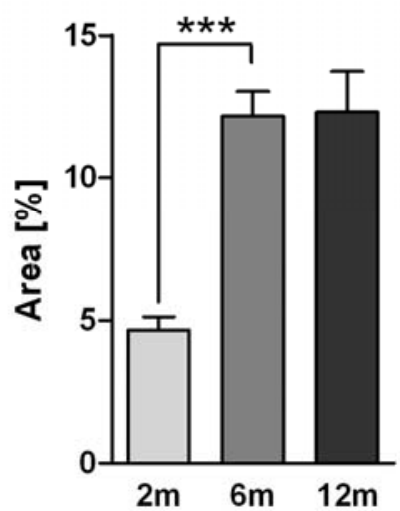

Thalamus

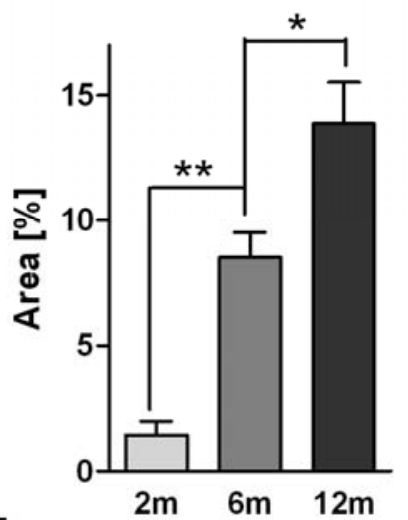

Abbildung 10 Plaqueload im Thalamus und Frontalkortex in Prozent Fläche der Gesamtfläche bei zwei, sechs und zwölf Monate alten Mäusen. *** $\mathrm{P}<0,001$; ** $\mathrm{P}<0,01 ; * \mathrm{P}<0,05$

\subsubsection{Anzahl der „Grains“}

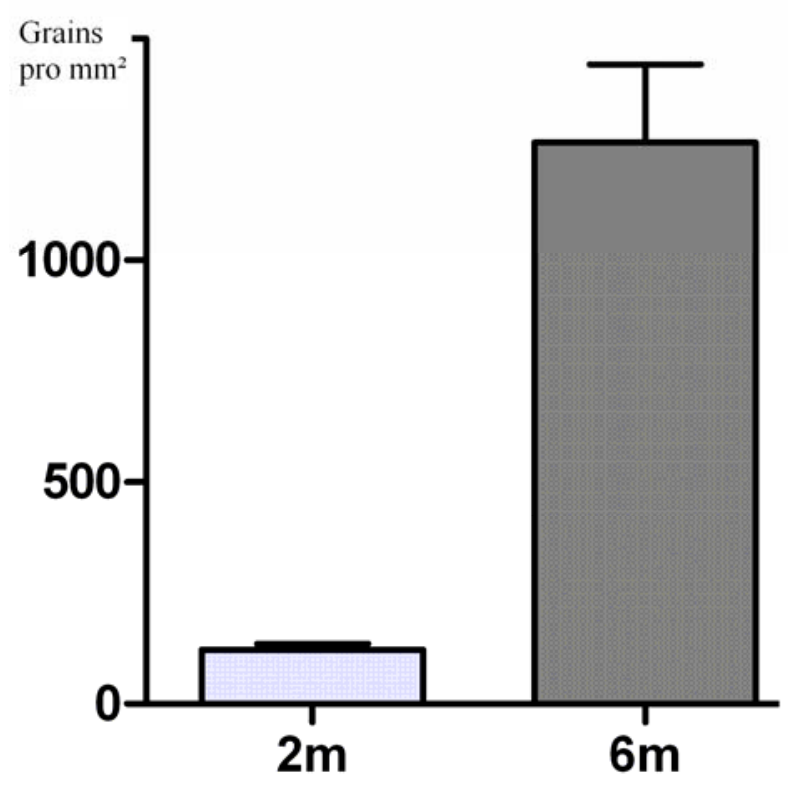

Die Messung der „Grains“ gibt Aufschluss darüber, ob sich im Verlauf des Lebens der untersuchten Mäuse die Anzahl Plaques ändert. Im Alter von zwei Monaten wurden 122 „Grains“ pro Quadratmillimeter gemessen. Bei den sechs Monate alten Mäusen wurden 1266,6 „Grains“ pro Quadratmillimeter gemessen. Das entspricht einer Verzehnfachung in vier Monaten.

Abbildung 11 Anzahl der gemessenen „Grains“ pro $\mathrm{mm}^{2}$ im Thalamus im Alter von zwei und sechs Monaten. 
Der nachfolgende Testansatz inklusive der zwölf Monate alten Mäuse ergab ähnliche Zahlen für den Thalamus. Es findet sich eine Verelffachung der „Grains“ zwischen dem ersten und dritten Messzeitpunkt.

Im Frontalkortex gibt es vom ersten zum zweiten Messzeitpunkt eine Zunahme um das 2,7fache. Der Unterschied zum dritten Messzeitpunkt zeigt auch eine positive Tendenz, ist aber nicht signifikant: $\mathrm{p}=0,075$.

Frontal Cortex

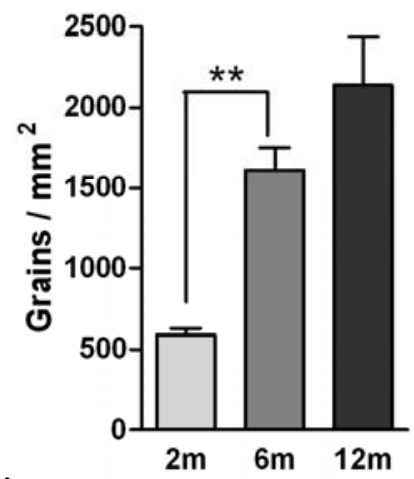

Thalamus

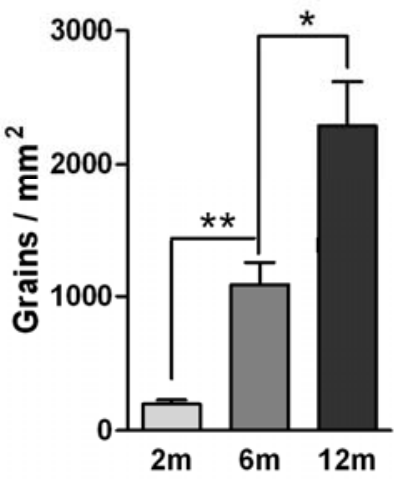

Abbildung 12 „Grains“ pro $\mathrm{mm}^{2}$ im Thalamus und Frontalkortex bei zwei, sechs und zwölf Monate alten Mäusen. ** $\mathrm{P}<0,01 ; * \mathrm{P}<0,05$

\subsubsection{Größe der ,Grains“}

Die Messung der durchschnittlichen Größe der „Grains“ erlaubt, eine Aussage über die Größenveränderung der A $\beta$-Ablagerungen zu treffen. Im Thalamus wurde nach

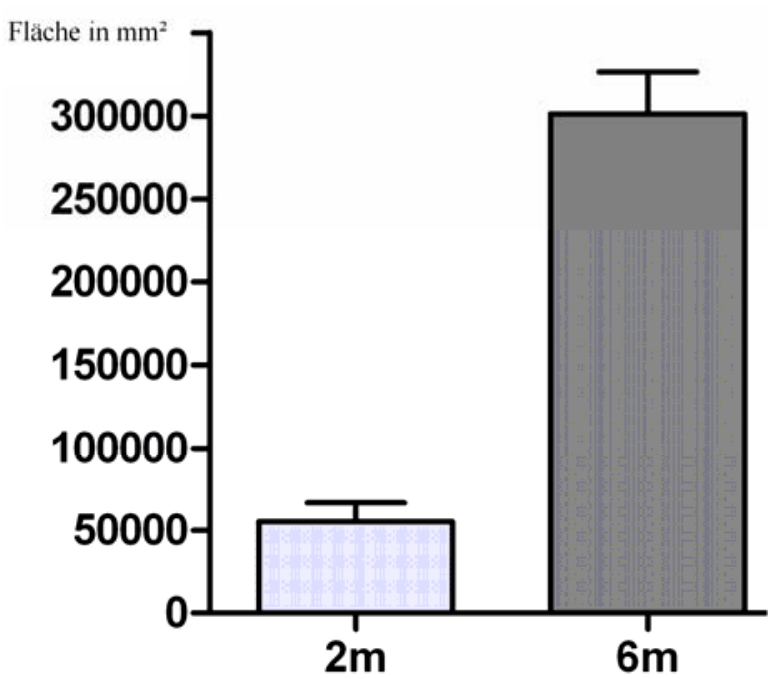
zwei Monaten Lebenszeit eine mittlere Plaquegröße von $55231 \mathrm{~mm}^{2}$ gemessen. Die Mäuse, die nach sechs Monaten gemessen wurden, hatten bis dahin „Grains“ entwickelt mit einer mittleren Größe von $301101 \mathrm{~mm}^{2}$. Die angefärbten Ablagerungen haben sich innerhalb von vier Monaten um den Faktor 5,5 vergrößert.

Abbildung 13 Durchschnittliche Größe in $\mathrm{mm}^{2}$ der angefärbten $\mathrm{A} \beta$-Ablagerungen im Thalamus im Alter von zwei und sechs Monaten.

Im folgenden neuen Testansatz mit den zwölf Monate alten Mäusen wurden folgende Ergebnisse ermittelt: Die im Thalamus gemessene Veränderung der Einzelkorngröße 
weist keine Signifikanz auf. Die im Frontalkortex gemessene Größenveränderung der $\mathrm{A} \beta$-Ablagerungen verändert sich nicht zwischen dem ersten und zweiten Messzeitpunkt. Zum dritten Messzeitpunkt hin findet eine signifikante $(p<0,05)$ Verkleinerung der Durchschnittsgröße statt.

Frontal Cortex

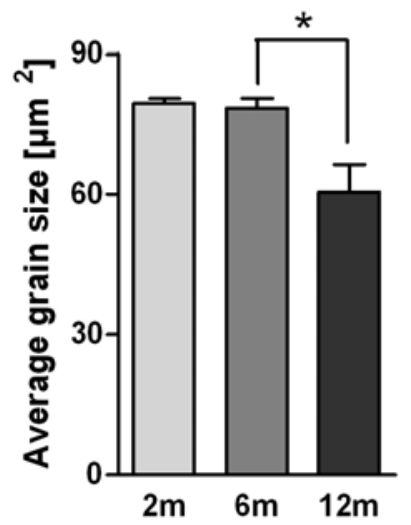

Thalamus

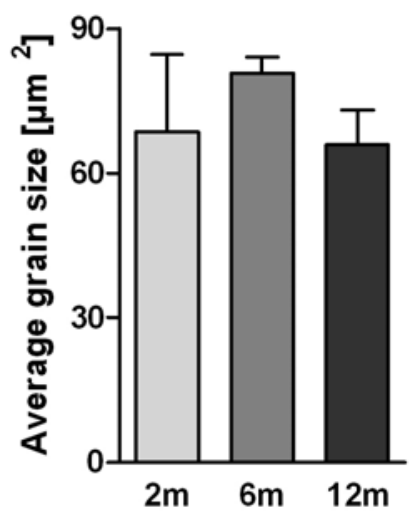

Abbildung 14 Durchschnittliche Größe der angefärbten A $\beta$-Ablagerungen im Thalamus und Frontalkortex im Alter von zwei, sechs und zwölf Monaten.

\subsection{Stereologie}

Die stereologische Untersuchung des Thalamus wurde, wie in Abbildung 1 abgegrenzt, durchgeführt. Es werden die Daten, die im Thalamus erhoben wurden, im Zusammenhang mit den Daten des Frontalkortex, die in einer anderen Arbeit (Kraus SL) erhoben wurden, gezeigt.

\subsubsection{Neuronenzahl}

Die im Thalamus gemessene Anzahl an Neuronen weist zu keinem Messzeitpunkt einen signifikanten Unterschied zwischen den verschiedenen Genotypen auf.

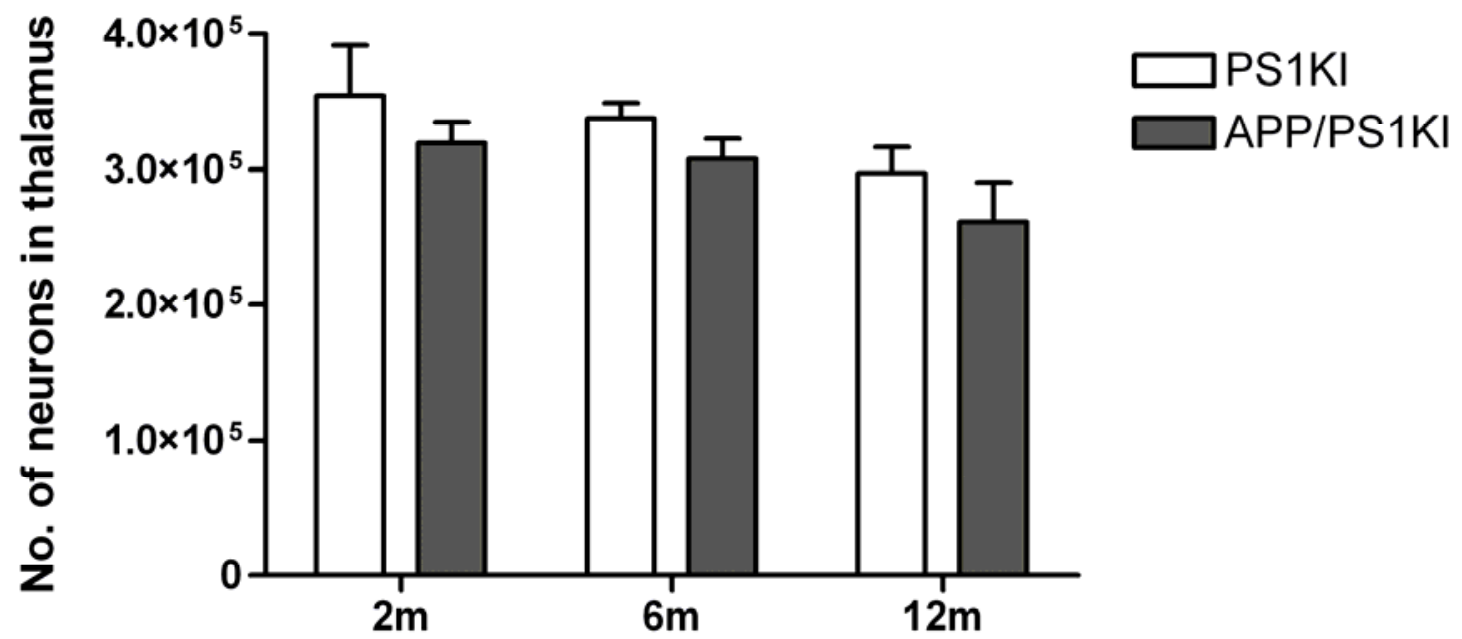


Abbildung 15 Anzahl der Neurone im Thalamus der Mäuse mit den verschiedenen Genotypen PS1KI und APP/PS1KI im Alter von zwei, sechs und zwölf Monaten.

Im Frontalkortex wurde bei den Mäusen mit dem Genotyp APP/PS1KI ein Nervenzellverlust von 28 und 35\% im Alter von sechs und zwölf Monaten festgestellt (beide $\mathrm{p}<0,001$ ). Die PS1KI-Kontrolltiere zeigen keinen Neuronenverlust.

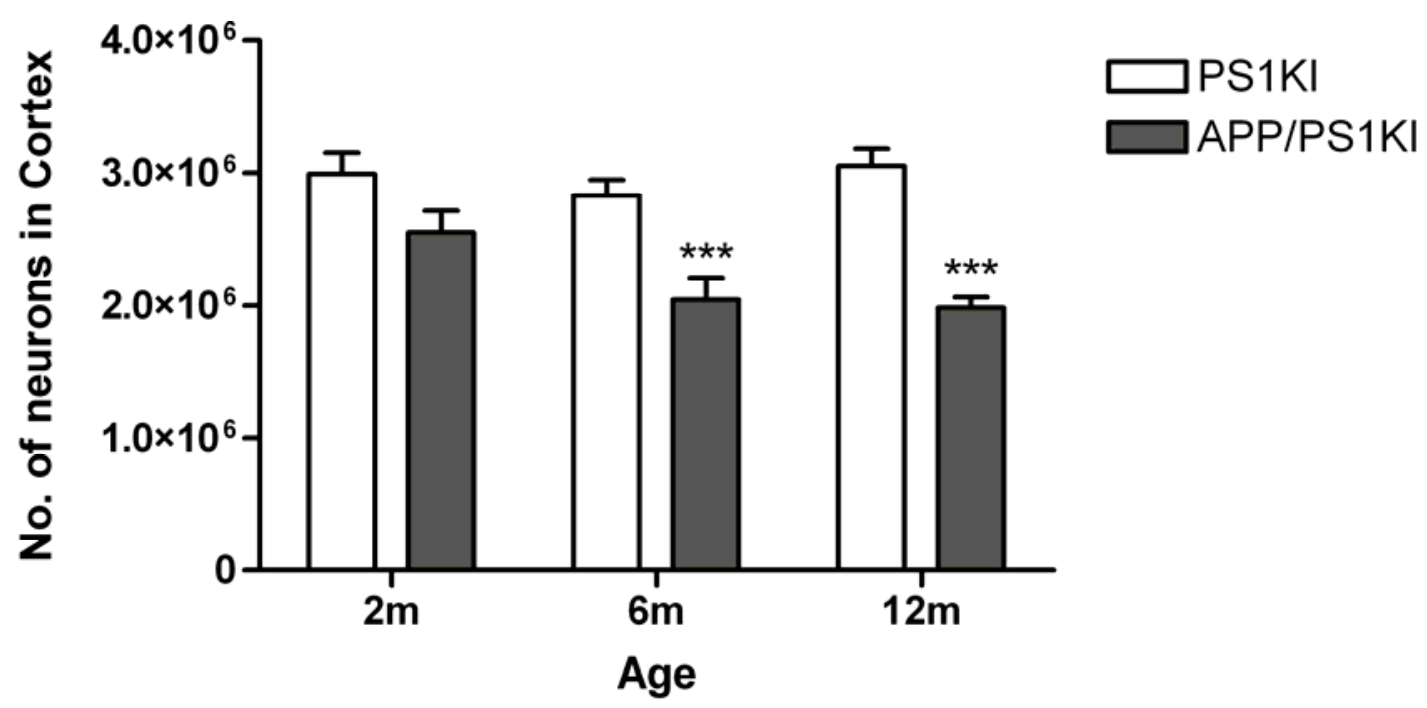

Abbildung 16 Anzahl der Neurone im Frontalkortex der Mäuse mit den verschiedenen Genotypen PS1KI und APP/PS1KI im Alter von zwei, sechs und zwölf Monaten.

\subsubsection{Volumen}

Der Vergleich der Volumina des Thalamus der beiden Genotypen, PS1KI und APP/PS1KI, zeigt zu keinem Messzeitpunkt einen signifikanten Unterschied. Die Volumenzunahme des Thalamus der PS1KI-Mäuse um 75\% von zwei zu sechs Monaten ist Ausdruck des normalen Wachstums. Hingegen hat das Thalamusvolumen der APP/PS1KI-Mäuse im gleichen Zeitraum nur um 30\% zugenommen. Der Unterschied ist mit $\mathrm{p}<0,072$ nicht signifikant. 


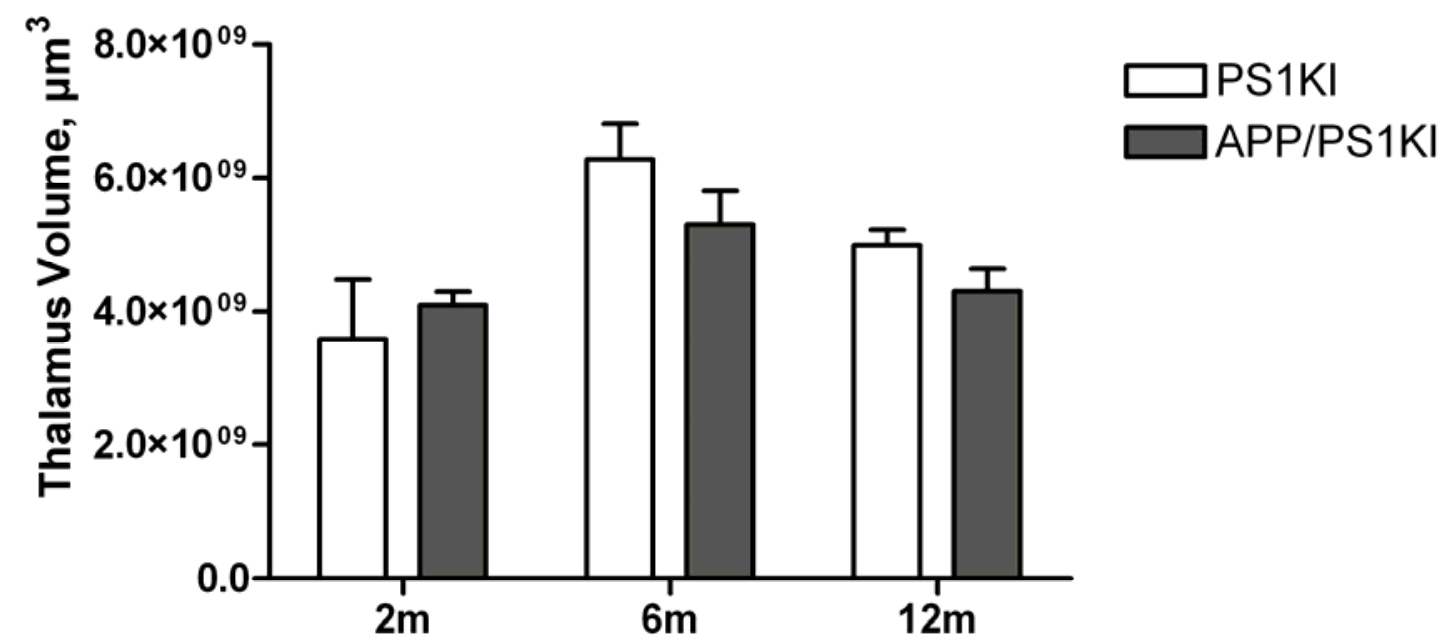

Abbildung 17 Volumina des Thalamus der zwei verschiedenen Genotypen PS1KI und APP/PS1KI zu den Zeitpunkten zwei, sechs und zwölf Monate.

Die Untersuchung des Frontalkortex zeigt im Vergleich der Mausgenotypen einen signifikanten Volumenunterschied zu den Messzeitpunkten nach sechs $(p<0,001)$ und zwölf $(p<0,01)$ Monaten. Im Zeitraum von zwei zu sechs Monaten hat das Frontalkortexvolumen der PS1KI-Kontrollmäuse um $86 \%$ zugenommen. Das entspricht dem normalen Wachstum der jungen Mäuse. Die APP/PS1KI-Mäuse zeigen eine verminderte Volumenzunahme von 50\% im gleichen Zeitraum.

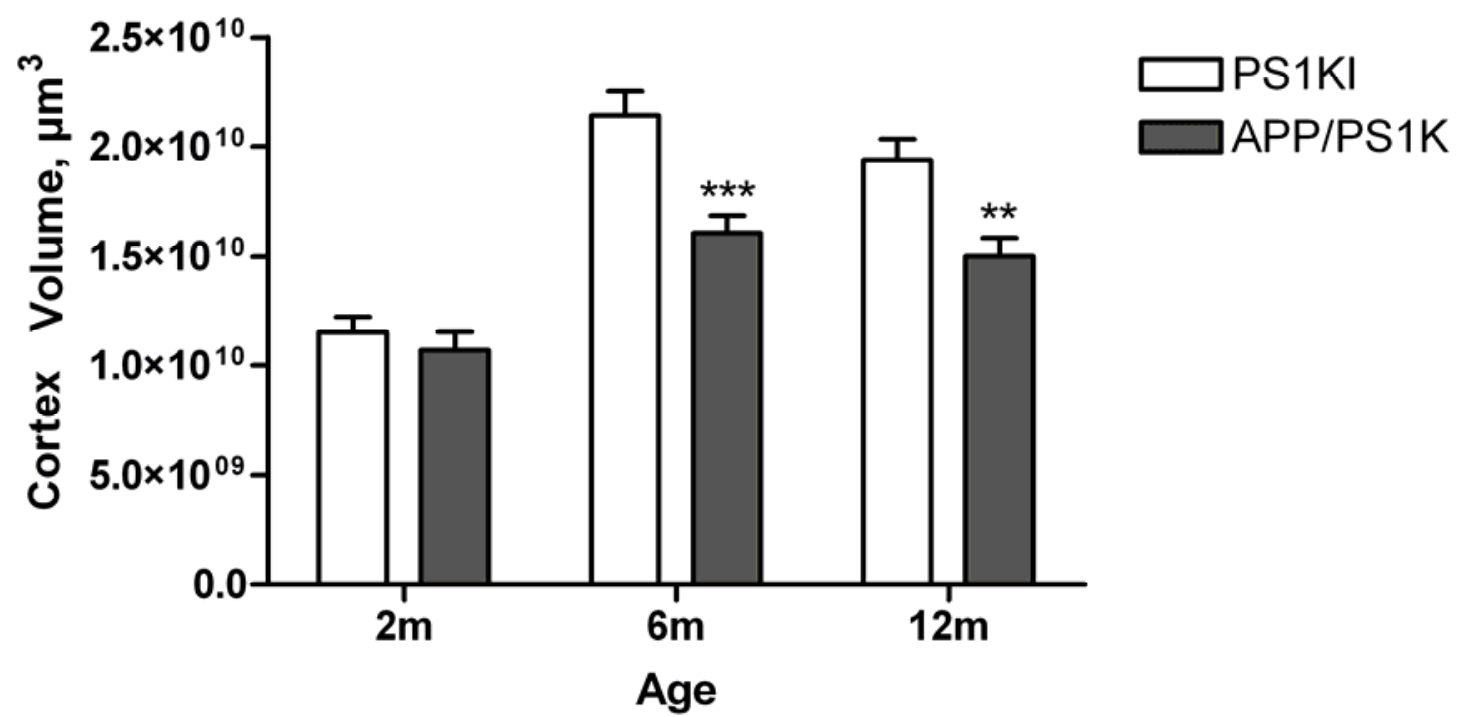

Abbildung 18 Volumina des Frontalkortex der zwei verschiedenen Genotypen PS1KI und APP/PS1KI zu den Zeitpunkten zwei, sechs und zwölf Monate. 


\section{Diskussion}

Eine vor kurzem veröffentlichte Studie aus dem Labor, in dem auch die vorliegende Arbeit entstand, zeigt eine Korrelation zwischen der intraneuronalen A $\beta$ Akkumulation und dem Untergang von Neuronen im cholinergen System in dem Mausmodell-APP/PS1KI. Dabei wurde beobachtet, dass der Neuronenuntergang sehr wahrscheinlich an die intraneuronale $A \beta$-Dosis gekoppelt ist. So wurde ein stärkerer und früher beginnender Neuronenverlust in einem motorischen Kerngebiet festgestellt, welches in stärkerem Ausmaß intraneuronales $A \beta$ aufwies als in einem Kerngebiet mit weniger intraneuronalem $A \beta$, das einen vergleichsweise geringeren Neuronenverlust erlitt (Christensen et al. 2008a). Diese Ergebnisse sprechen stark für die Hypothese, dass das intrazelluläre $\beta$-Amyloid einen Hauptauslöser für die Alzheimer-Erkrankung darstellt. Die vorliegende Arbeit ist Teil einer Untersuchung, die den Einfluss der intraneuronalen $A \beta$-Toxizität im Vergleich zu Plaques auf das neuronale Überleben analysiert. Dafür wurden zwei Hirnregionen ausgesucht, die sich, bezüglich der sich entwickelnden Pathologien, bedeutend unterscheiden. Für die stereologische Quantifikation ist der Kortex, welcher in einer anderen zeitgleich erstellten Promotionsarbeit untersucht wurde, gewählt worden, weil er eine Hirnregion darstellt, die sehr früh und in hohem Maße intraneuronales $\mathrm{A} \beta$ entwickelt und in der auch eine Plaquebildung besteht. Im Vergleich dazu wurde der Thalamus gewählt, dessen stereologische Quantifikation Bestandteil dieser Promotionsarbeit ist, weil er eine Region darstellt, in dem kein intraneuronales $\beta$-Amyloid vorkommt und nur Plaquebildung besteht.

Im Alter von 12 Monaten weisen beide Regionen eine ähnliche Plaquebedeckung auf: $12,1 \%$ im Kortex und 13,1\% im Thalamus. Obwohl es im Thalamus zu diesen massiven Plaqueablagerungen kommt, zeigte sich bei den sechs und zwölf Monate alten Tieren kein Neuronenverlust in den APP/PS1KI-Mäusen im Vergleich zu den PS1KI-Kontrollmäusen. Diese Beobachtung passt zu den Ergebnissen aus anderen Studien mit AD-Mausmodellen, in denen auch keine Korrelation zwischen dem Ausmaß der A $\beta$-Plaquepathologie und dem Ausmaß des Neuronenverlustes gefunden wurde (Duyckaerts et al. 2008). Diese Ergebnisse sprechen dafür, dass die Plaques keinen signifikanten Einfluss auf das neuronale Überleben darstellen und so keine Ursache für den Neuronenuntergang bei der Alzheimer-Demenz sind. Des Weiteren wird diese Überlegung gestützt durch die Ergebnisse der parallel erstellten 
Promotionsarbeit, die im Kortex derselben Mäuse ermittelt wurden. Im Alter von 6 Monaten wurde ein Neuronenuntergang im Kortex von etwa 30\% festgestellt, welcher bis zum Alter von zwölf Monaten nicht signifikant zunahm. Der einzige offensichtliche Unterschied der beiden untersuchten Regionen war, dass im Kortex eine starke temporäre Akkumulation von intraneuronalem $\mathrm{A} \beta$ stattfand. Aufgrund dieser Beobachtung ist stark anzunehmen, dass die, den Plaques vorausgehenden, $\beta$ Amyloid-Ablagerungen einen Hauptauslöser für den Neuronenverlust im Kortex darstellen. Dennoch lässt sich aber nicht ausschließen, dass sich die thalamischen Neurone in ihren zellulären Eigenschaften von den kortikalen unterscheiden und so eventuell insgesamt robuster sind. Des Weiteren wäre möglich, dass das PS1-Gen alleine bereits eine toxische Wirkung hat. Dagegen spricht, dass untersuchte Kontrollmäuse, die nur für PS1KI positiv waren, keinen Neuronenverlust im Verlauf des Lebens erlitten, weder im Thalamus noch im Kortex. So lässt sich vermuten, dass PS1-Mutationen keinen Einfluss auf das neuronale Überleben bei der familiären Alzheimer-Erkrankung haben. Lediglich in Kombination mit APP kommt es zu einem $A \beta$-vermittelten Untergang von Neuronen.

Die Hypothese, dass das intrazelluläre $\beta$-Amyloid einen zytotoxischen Effekt auf Neurone hat, wird durch die Beobachtung gestützt, dass der Neuronenverlust im Alter von sechs Monaten sichtbar wurde und gleichzeitig verringerte intraneuronale $A \beta$ Ablagerungen gefunden wurden. So könnte es sein, dass Neurone früh viel $\beta$-Amyloid intrazellulär akkumulieren und dadurch im Alter von zwei bis vier Monaten untergehen. Diese Überlegung passt zu den Ergebnissen einer Untersuchung, welche belegen, dass Neurone, die früh intrazelluläres $A \beta$ bilden, untergehen und die Überreste Ursprungsorte für Plaques bilden (D'Andrea et al. 2001). Weiterhin gibt es noch andere Hypothesen für die Bildung von Plaques: z.B. haben dichte kompakte Plaques im Zusammenhang mit einem hohen A $\beta 40$-Vorkommen eine andere Ätiologie als die diffusen Plaques, die zum Großteil aus der A $\beta 42$-Isoform bestehen, wie in dem hier verwendeten Mausmodell. Der transiente Charakter der intraneuronalen A $\beta$ Ablagerungen, die dem Neuronenverlust vorausgehen, wurde auch in anderen Untersuchungen an APP/PS1-Mäusen beschrieben (Wirths et al. 2002; Langui et al. 2004). Die Bedeutung der frühen temporären $A \beta$-Akkumulation in den Neuronen wird auch durch Ergebnisse von Untersuchungen an Trisomie-21-Patienten gestützt, die wie auch AD-Patienten Plaques und neurofibrilläre Tangles entwickeln. Demnach werden intraneuronale A $\beta 42-P e p t i d-A k k u m u l a t i o n e n$ nur in den Gehirnen jüngerer Down- 
Syndrom-Patienten gefunden, die mit zunehmendem Alter weniger werden, während die Bildung von Plaques mit dem Alter zunimmt (Gyure et al. 2001; Mori et al. 2002). Dazukommend wird in einer weiteren Studie berichtet, dass intraneuronales A $\beta 42$ nur bei Alzheimer-Demenz-Erkrankten $\mathrm{zu}$ finden ist, die ein niedriges Braak-Level aufweisen und eine kurze Erkrankungsdauer haben, und dass die intraneuronale A $\beta$ Immunreaktivität mit dem Fortschreiten der Erkrankung abnimmt (Gouras et al. 2000). Weiterhin sprechen auch die Ergebnisse von West et al. für diese Hypothese. Sie fanden heraus, dass Patienten, die noch keine AD-typischen Symptome zeigen und sich also zeitlich vor dem Erkrankungsbeginn befinden, bereits intrazelluläre A $\beta 42$ Ablagerungen haben. Später mit dem Auftreten der klinischen Symptome der AD ist die messbare intrazelluläre Immunreaktivität stark verringert, was auf den Neuronenuntergang zurückzuführen ist (West et al. 2004). Demgegenüber stehen Ergebnisse von Wegiel et. al. Sie konnten bei Trisomie-21- und Kontrollpatienten über die gesamte Lebensspanne verteilt eine positive Immunreaktivität gegen intraneuronales $A \beta$ messen. Unter diesem Gesichtspunkt betrachtet, könnte dies Ausdruck eines normalen Metabolismus der Neurone sein (Wegiel et al. 2007).

Die Annahme, dass das intraneuronale $\mathrm{A} \beta$ nur temporär vorkommt, und der Beweis dafür, ist entscheidend für die Hypothese des intrazellulär vorkommenden A $\beta$. Denn die temporäre intrazelluläre $\mathrm{A} \beta$-Pathologie in humanem Hirngewebe von ADPatienten nachzuweisen, stellt ein Problem dar, weil bei Auftreten von Symptomen bereits ein Neuronenuntergang eingetreten ist und es somit nicht mehr möglich ist, intrazelluläres $\beta$-Amyloid darzustellen.

Insgesamt weisen die Ergebnisse dieser Arbeit, zusammen mit den Ergebnissen aus der Promotionsarbeit, die die Untersuchung des Kortex als Aufgabe hatte, in die Richtung, dass Plaques keinen Einfluss auf das Überleben von Neuronen haben. Stattdessen überschneidet sich eine temporäre Akkumulation von intraneuronalem BAmyloid mit dem Verlust von Neuronen. Es ist eher unwahrscheinlich, dass die extrazellulär löslichen A $\beta$-Oligomere die festgestellten neurotoxischen Effekte verursachen, denn sonst müssten diese Pathologien in all den Regionen zu finden sein, in denen viele Plaques vorkommen, wie auch im Thalamus. Im Ganzen betrachtet, passen die Ergebnisse gut zu der modifizierten $\beta$-Amyloid-Kaskaden-Hypothese, welche besagt, dass die frühe intraneuronale Akkumulation von $\beta$-Amyloid der Hauptpathomechanismus ist und dass die Bildung extrazellulärer $\beta$-Amyloid-Plaques erst später erfolgt (Wirths et al. 2004). 
Andererseits muss berücksichtigt werden, dass die Ergebnisse nicht direkt auf Alzheimer-Erkrankung beim Menschen übertragbar sind. Das untersuchte Mausmodell beinhaltet gleich mehrere Mutationen, die beim Menschen nur einzeln anzutreffen sind. Zudem sind die meisten Alzheimer-Erkrankungen sporadisch, bzw. nicht auf eines der Gene, die im APP/PS1KI-Mausmodell verwendet wurden, zurückzuführen. Gegen eine direkte Übertragung der Ergebnisse auf den Menschen spricht auch der Zeitraum, in dem sich die Erkrankung und ihre typischen neuropathologischen Veränderungen entwickeln. In dem verwendeten Mausmodell sind erste Plaques bereits nach zwei Monaten nachweisbar und nach 12 Monaten ist ein signifikanter Neuronenverlust zu beobachten. Beim Menschen ist die Alzheimer-Erkrankung ein Prozess, der sich über Jahre bis Jahrzehnte hinziehen kann. Darüber hinaus werden auch nicht alle neuropathologischen Veränderungen, die beim Menschen vorkommen, in diesem Mausmodell imitiert. Die beim Menschen beschriebenen Tau-Pathologien werden in dem APP/PS1KI-Mausmodell nicht berücksichtigt. 


\section{Zusammenfassung}

Die Akkumulation von $\beta$-Amyloid-Plaques und neurofibrillären Tangles, die aus hyperphosphoryliertem Tau-Protein bestehen, sind typische pathologische Veränderungen, welche bei der Alzheimer-Erkrankung (AD) vorkommen. Die dafür verantwortlichen mutierten humanen Gene werden zur Erforschung in transgenen Mäusen exprimiert, mit der Folge, dass die AD-typischen Pathologien in den Mausgehirnen auftreten. Der Neuronenuntergang, der typisch für die AD ist, tritt auch bei transgenen Mäusen auf und ist von großer Bedeutung, da in ihm die Ursache für die AD-typischen Symptome, wie z.B. Gedächtnisstörungen, zu sehen ist. Dabei spielt das $A \beta$ eine entscheidende Rolle, wobei noch unklar ist, auf welche Art und Weise das A $\beta$ mit dem Neuronenuntergang zusammenhängt. Diese Arbeit ist Teil einer Untersuchung, welche den Einfluss von extrazellulären $\beta$-Amyloid-Plaques im Vergleich $\mathrm{zu}$ intraneuronalen $\mathrm{A} \beta$ untersucht. Dazu wurde der Thalamus von APP/PS1KI-Mäusen stereologisch untersucht, in dem Plaques vorkommen, aber kein intraneuronales A $\beta$. Zum Vergleich wurde in einer parallel erstellten Promotionsarbeit (verfasst von Sophie Kraus) der Kortex derselben Mäuse untersucht, in dem neben Plaques auch intraneuronales $A \beta$ vorkommt. So wurde im Alter von 6 Monaten ein Neuronenuntergang festgestellt und gleichzeitig eine verminderte intraneuronale $A \beta$ Immunreaktivität gemessen. Bemerkenswerterweise wurde im Thalamus kein Neuronenuntergang festgestellt, obwohl es zu einer Plaquebildung kam, die ähnlich stark ausgeprägt war wie im Kortex. Folglich weisen die Ergebnisse beider Promotionsarbeiten darauf hin, dass die extrazellulären $\beta$-Amyloid-Plaques keinen Einfluss auf den Untergang der Neurone haben. Eher scheint das vorübergehend vorkommende intrazelluläre $A \beta$ von Bedeutung zu sein, welches als früh eintretendes pathologisches Zeichen ausschlaggebend für den Neuronenverlust sein könnte. 


\section{Literaturverzeichnis}

Alzheimer A, Stelzmann RA, Schnitzlein HN, Murtagh FR (1995):An English translation of Alzheimer's 1907 paper, "Uber eine eigenartige Erkankung der Hirnrinde".Clin Anat. $\underline{8}$, $429-431$

Andersen K, Launer LJ, Dewey ME, Letenneur L, Ott A, Copeland JR, Dartigues JF, KraghSorensen P, Baldereschi M, Brayne C, Lobo A, Martinez-Lage JM, Stijnen T und Hofman A (1999): Gender differences in the incidence of AD and vascular dementia: The EURODEM Studies. EURODEM Incidence Research Group. Neurology $\underline{53}$, 1992-7

Arnold SE, Hyman BT, Flory J, Damasio AR und Van Hoesen GW (1991): The topographical and neuroanatomical distribution of neurofibrillary tangles and neuritic plaques in the cerebral cortex of patients with Alzheimer's disease. Cereb Cortex $\underline{1}, 103-16$

Barnes LL, Wilson RS, Bienias JL, Schneider JA, Evans DA und Bennett DA (2005): Sex differences in the clinical manifestations of Alzheimer disease pathology. Arch Gen Psychiatry $\underline{62}, 685-91$

Barrett-Connor E und Kritz-Silverstein D (1993): Estrogen replacement therapy and cognitive function in older women. JAMA $\underline{269}, 2637-41$

Bickel H (2000): [Dementia syndrome and Alzheimer disease: an assessment of morbidity and annual incidence in Germany]. Gesundheitswesen $\underline{62}, 211-8$

Blacker D, Wilcox MA, Laird NM, Rodes L, Horvath SM, Go RC, Perry R, Watson B, Jr., Bassett SS, McInnis MG, Albert MS, Hyman BT und Tanzi RE (1998): Alpha-2 macroglobulin is genetically associated with Alzheimer disease. Nat Genet $\underline{19}$, 357-60

Blöchlinger B. (2007). "BrainFair 2007 zu Prävention und Rehabilitation." Heruntergeladen am 06. März, 2009, von http://www.uzh.ch/news/articles/2006/2475.html.

Böcker W, Denk H und Heitz U: Pathologie. 3. ed.; Elsevier, München 2004 
Bondareff W, Mountjoy CQ und Roth M (1981): Selective loss of neurones of origin of adrenergic projection to cerebral cortex (nucleus locus coeruleus) in senile dementia. Lancet $\underline{1981,1,783-4}$

Borchelt DR, Thinakaran G, Eckman CB, Lee MK, Davenport F, Ratovitsky T, Prada CM, Kim G, Seekins S, Yager D, Slunt HH, Wang R, Seeger M, Levey AI, Gandy SE, Copeland NG, Jenkins NA, Price DL, Younkin SG und Sisodia SS (1996): Familial Alzheimer's disease-linked presenilin 1 variants elevate Abeta1-42/1-40 ratio in vitro and in vivo. Neuron $\underline{17}, 1005-13$

Braak H und Braak E (1991): Neuropathological stageing of Alzheimer-related changes. Acta Neuropathol $\underline{82}, 239-59$

Buxbaum JD, Liu KN, Luo Y, Slack JL, Stocking KL, Peschon JJ, Johnson RS, Castner BJ, Cerretti DP und Black RA (1998): Evidence that tumor necrosis factor alpha converting enzyme is involved in regulated alpha-secretase cleavage of the Alzheimer amyloid protein precursor. J Biol Chem $\underline{273}$, 27765-7

Casas C, Sergeant N, Itier JM, Blanchard V, Wirths O, van der Kolk N, Vingtdeux V, van de Steeg E, Ret G, Canton T, Drobecq H, Clark A, Bonici B, Delacourte A, Benavides J, Schmitz C, Tremp G, Bayer TA, Benoit P und Pradier L (2004): Massive CA1/2 neuronal loss with intraneuronal and N-terminal truncated Abeta42 accumulation in a novel Alzheimer transgenic model. Am J Pathol $\underline{165}, 1289-300$

Chartier-Harlin MC, Crawford F, Houlden H, Warren A, Hughes D, Fidani L, Goate A, Rossor M, Roques P, Hardy J und et al. (1991): Early-onset Alzheimer's disease caused by mutations at codon 717 of the beta-amyloid precursor protein gene. Nature $\underline{353}, 844-6$

Christensen DZ, Bayer TA und Wirths O (2008a): Intracellular Abeta triggers neuron loss in the cholinergic system of the APP/PS1KI mouse model of Alzheimer's disease. Neurobiol Aging, Onlinepublikation: http://dx.doi.org/10.1016/j.neurobiolaging.2008.07.022 
Christensen DZ, Kraus SL, Flohr A, Cotel MC, Wirths O und Bayer TA (2008b): Transient intraneuronal A beta rather than extracellular plaque pathology correlates with neuron loss in the frontal cortex of APP/PS1KI mice. Acta Neuropathol $\underline{116}, 647-55$

Coleman PD und Yao PJ (2003): Synaptic slaughter in Alzheimer's disease. Neurobiol Aging $\underline{24}, 1023-7$

Corder EH, Saunders AM, Strittmatter WJ, Schmechel DE, Gaskell PC, Small GW, Roses AD, Haines JL und Pericak-Vance MA (1993): Gene dose of apolipoprotein E type 4 allele and the risk of Alzheimer's disease in late onset families. Science 261, 921-3

Corder EH, Saunders AM, Risch NJ, Strittmatter WJ, Schmechel DE, Gaskell PC, Jr., Rimmler JB, Locke PA, Conneally PM, Schmader KE und et al. (1994): Protective effect of apolipoprotein E type 2 allele for late onset Alzheimer disease. Nat Genet $\underline{7}, 180-4$

Cummings JL, Vinters HV, Cole GM und Khachaturian ZS (1998): Alzheimer's disease: etiologies, pathophysiology, cognitive reserve, and treatment opportunities. Neurology $\underline{51}$, S2-17; discussion S65-7

D'Andrea MR, Nagele RG, Wang HY, Peterson PA und Lee DH (2001): Evidence that neurones accumulating amyloid can undergo lysis to form amyloid plaques in Alzheimer's disease. Histopathology $\underline{38}, 120-34$

Davies CA, Mann DM, Sumpter PQ und Yates PO (1987): A quantitative morphometric analysis of the neuronal and synaptic content of the frontal and temporal cortex in patients with Alzheimer's disease. J Neurol Sci $\underline{78}, 151-64$

De Strooper B (2003): Aph-1, Pen-2, and Nicastrin with Presenilin generate an active gammaSecretase complex. Neuron $\underline{38}, 9-12$

DIMDI: ICD-10-GM. DIMDI, Köln 2009. Heruntergeladen am 05. März, 2009, von http:/www.dimdi.de/static/de/klassi/diagnosen/icd10/htmlgm2009/block-f00-f09.htm 
Duyckaerts C, Potier MC und Delatour B (2008): Alzheimer disease models and human neuropathology: similarities and differences. Acta Neuropathol 115, 5-38

French LR, Schuman LM, Mortimer JA, Hutton JT, Boatman RA und Christians B (1985): A case-control study of dementia of the Alzheimer type. Am J Epidemiol 121, 414-21

Gatz M, Svedberg P, Pedersen NL, Mortimer JA, Berg S und Johansson B (2001): Education and the risk of Alzheimer's disease: findings from the study of dementia in Swedish twins. J Gerontol B Psychol Sci Soc Sci $\underline{56}$, P292-300

Goate A, Chartier-Harlin MC, Mullan M, Brown J, Crawford F, Fidani L, Giuffra L, Haynes A, Irving N, James L und et al. (1991): Segregation of a missense mutation in the amyloid precursor protein gene with familial Alzheimer's disease. Nature $\underline{349}$, 704-6

Gouras GK, Tsai J, Naslund J, Vincent B, Edgar M, Checler F, Greenfield JP, Haroutunian V, Buxbaum JD, $\mathrm{Xu} \mathrm{H}$, Greengard $\mathrm{P}$ und Relkin NR (2000): Intraneuronal Abeta42 accumulation in human brain. Am J Pathol $\underline{156}, 15-20$

Graves AB, White E, Koepsell TD, Reifler BV, van Belle G, Larson EB und Raskind M (1990): The association between head trauma and Alzheimer's disease. Am J Epidemiol 131, $491-501$

Gyure KA, Durham R, Stewart WF, Smialek JE und Troncoso JC (2001): Intraneuronal abeta-amyloid precedes development of amyloid plaques in Down syndrome. Arch Pathol Lab Med $\underline{125}$, 489-92

Haass C, Lemere CA, Capell A, Citron M, Seubert P, Schenk D, Lannfelt L und Selkoe DJ (1995): The Swedish mutation causes early-onset Alzheimer's disease by beta-secretase cleavage within the secretory pathway. Nat Med $\underline{1}, 1291-6$

Hamos JE, DeGennaro LJ und Drachman DA (1989): Synaptic loss in Alzheimer's disease and other dementias. Neurology $\underline{39}, 355-61$ 
Hardy J und Allsop D (1991): Amyloid deposition as the central event in the aetiology of Alzheimer's disease. Trends Pharmacol Sci 12, 383-8

Henderson VW, Paganini-Hill A, Emanuel CK, Dunn ME und Buckwalter JG (1994): Estrogen replacement therapy in older women. Comparisons between Alzheimer's disease cases and nondemented control subjects. Arch Neurol 51, 896-900

Hof PR, Glannakopoulos P und Bouras C (1996): The neuropathological changes associated with normal brain aging. Histol Histopathol 11, 1075-88

Honer WG, Dickson DW, Gleeson J und Davies P (1992): Regional synaptic pathology in Alzheimer's disease. Neurobiol Aging $\underline{13}, 375-82$

Jenkinson ML, Bliss MR, Brain AT und Scott DL (1989): Rheumatoid arthritis and senile dementia of the Alzheimer's type. Br J Rheumatol $\underline{28}, 86-8$

Jorm AF und Jolley D (1998): The incidence of dementia: a meta-analysis. Neurology $\underline{51}$, 728-33

Kandel ER, Schwartz JH und Jessell TM: Principles of neural science. $4^{\text {th }}$ edition; McGrawHill, Health Professions Division, New York 2000

Kang J, Lemaire HG, Unterbeck A, Salbaum JM, Masters CL, Grzeschik KH, Multhaup G, Beyreuther K und Muller-Hill B (1987): The precursor of Alzheimer's disease amyloid A4 protein resembles a cell-surface receptor. Nature $\underline{325}, 733-6$

Katzman R, Terry R, DeTeresa R, Brown T, Davies P, Fuld P, Renbing X und Peck A (1988): Clinical, pathological, and neurochemical changes in dementia: a subgroup with preserved mental status and numerous neocortical plaques. Ann Neurol 23, 138-44

Kraszpulski M, Soininen H, Helisalmi S und Alafuzoff I (2001): The load and distribution of beta-amyloid in brain tissue of patients with Alzheimer's disease. Acta Neurol Scand 103, 8892 
Kraus SL: Untersuchungen $\mathrm{zu}$ pathologischen Veränderungen im Frontalkortex beim Alzheimer-Modell APP/PS1KI. Med. Diss. (2009), Göttingen in Vorbereitung (mit freundlicher Genehmigung der Verfasserin)

Kril JJ, Hodges J und Halliday G (2004): Relationship between hippocampal volume and CA1 neuron loss in brains of humans with and without Alzheimer's disease. Neurosci Lett $\underline{361}, 9-12$

Lammich S, Kojro E, Postina R, Gilbert S, Pfeiffer R, Jasionowski M, Haass C und Fahrenholz F (1999): Constitutive and regulated alpha-secretase cleavage of Alzheimer's amyloid precursor protein by a disintegrin metalloprotease. Proc Natl Acad Sci U S A $\underline{96}$, $3922-7$

Langui D, Girardot N, El Hachimi KH, Allinquant B, Blanchard V, Pradier L und Duyckaerts C (2004): Subcellular topography of neuronal Abeta peptide in APPxPS1 transgenic mice. Am J Pathol 165, 1465-77

Lorenzo A und Yankner BA (1994): Beta-amyloid neurotoxicity requires fibril formation and is inhibited by congo red. Proc Natl Acad Sci U S A $\underline{91}$, 12243-7

Manly JJ, Merchant CA, Jacobs DM, Small SA, Bell K, Ferin M und Mayeux R (2000): Endogenous estrogen levels and Alzheimer's disease among postmenopausal women. Neurology $\underline{54}, 833-7$

Masuhr KF und Neumann M: Neurologie. Georg Thieme Verlag, Stuttgart 2007

McGeer PL und McGeer EG (1996): Anti-inflammatory drugs in the fight against Alzheimer's disease. Ann N Y Acad Sci $\underline{777}, 213-20$

McGeer PL, Schulzer M und McGeer EG (1996): Arthritis and anti-inflammatory agents as possible protective factors for Alzheimer's disease: a review of 17 epidemiologic studies. Neurology $\underline{47}, 425-32$ 
McKenzie JE, Gentleman SM, Roberts GW, Graham DI und Royston MC (1994): Increased numbers of beta APP-immunoreactive neurones in the entorhinal cortex after head injury. Neuroreport $\underline{6}, 161-4$

Mori C, Spooner ET, Wisniewsk KE, Wisniewski TM, Yamaguch H, Saido TC, Tolan DR, Selkoe DJ und Lemere CA (2002): Intraneuronal Abeta42 accumulation in Down syndrome brain. Amyloid $\underline{9}, 88-102$

Morrison JH und Hof PR (1997): Life and death of neurons in the aging brain. Science 278, $412-9$

Mortel KF und Meyer JS (1995): Lack of postmenopausal estrogen replacement therapy and the risk of dementia. J Neuropsychiatry Clin Neurosci $\underline{7}, 334-7$

Mortimer JA, French LR, Hutton JT und Schuman LM (1985): Head injury as a risk factor for Alzheimer's disease. Neurology $\underline{35}, 264-7$

Mortimer JA, Snowdon DA und Markesbery WR (2003): Head circumference, education and risk of dementia: findings from the Nun Study. J Clin Exp Neuropsychol 25, 671-9

Mullan M, Crawford F, Axelman K, Houlden H, Lilius L, Winblad B und Lannfelt L (1992): A pathogenic mutation for probable Alzheimer's disease in the APP gene at the N-terminus of beta-amyloid. Nat Genet $\underline{1}, 345-7$

Mullan M, Tsuji S, Miki T, Katsuya T, Naruse S, Kaneko K, Shimizu T, Kojima T, Nakano I, Ogihara T und et al. (1993): Clinical comparison of Alzheimer's disease in pedigrees with the codon 717 Val-->Ile mutation in the amyloid precursor protein gene. Neurobiol Aging $\underline{14}$, 407-19

Nagy Z, Hindley NJ, Braak H, Braak E, Yilmazer-Hanke DM, Schultz C, Barnetson L, Jobst KA und Smith AD (1999): Relationship between clinical and radiological diagnostic criteria for Alzheimer's disease and the extent of neuropathology as reflected by 'stages': a prospective study. Dement Geriatr Cogn Disord 10, 109-14 
Ott A, Breteler MM, van Harskamp F, Claus JJ, van der Cammen TJ, Grobbee DE und Hofman A (1995): Prevalence of Alzheimer's disease and vascular dementia: association with education. The Rotterdam study. BMJ $\underline{310}$, 970-3

Paxinos G und Franklin KBJ: The mouse brain in stereotaxic coordinates. $2^{\text {nd }}$ edition; Academic Press, New York 2001

Phillips SM und Sherwin BB (1992): Effects of estrogen on memory function in surgically menopausal women. Psychoneuroendocrinology $\underline{17}$, 485-95

Pschyrembel W: Klinisches Wörterbuch. 261. Auflage; W. de Gruyter, Berlin 2007, S. 403 s.v. "Demenz"

Rapp SR, Espeland MA, Shumaker SA, Henderson VW, Brunner RL, Manson JE, Gass ML, Stefanick ML, Lane DS, Hays J, Johnson KC, Coker LH, Dailey M und Bowen D (2003): Effect of estrogen plus progestin on global cognitive function in postmenopausal women: the Women's Health Initiative Memory Study: a randomized controlled trial. JAMA $\underline{289}, 2663-72$

Roberts GW, Gentleman SM, Lynch A, Murray L, Landon M und Graham DI (1994): Beta amyloid protein deposition in the brain after severe head injury: implications for the pathogenesis of Alzheimer's disease. J Neurol Neurosurg Psychiatry 57, 419-25

Rogaeva E (2002): The solved and unsolved mysteries of the genetics of early-onset Alzheimer's disease. Neuromolecular Med 2, 1-10

Saunders AM, Strittmatter WJ, Schmechel D, George-Hyslop PH, Pericak-Vance MA, Joo SH, Rosi BL, Gusella JF, Crapper-MacLachlan DR, Alberts MJ und et al. (1993): Association of apolipoprotein E allele epsilon 4 with late-onset familial and sporadic Alzheimer's disease. Neurology $\underline{43}, 1467-72$

Schmitz C und Hof PR (2005): Design-based stereology in neuroscience. Neuroscience 130, 813-31

Selkoe DJ (2001): Alzheimer's disease: genes, proteins, and therapy. Physiol Rev $\underline{81}$, 741-66 
Strittmatter WJ, Saunders AM, Schmechel D, Pericak-Vance M, Enghild J, Salvesen GS und Roses AD (1993): Apolipoprotein E: high-avidity binding to beta-amyloid and increased frequency of type 4 allele in late-onset familial Alzheimer disease. Proc Natl Acad Sci U S A 90, $1977-81$

Suzuki N, Cheung TT, Cai XD, Odaka A, Otvos L, Jr., Eckman C, Golde TE und Younkin SG (1994): An increased percentage of long amyloid beta protein secreted by familial amyloid beta protein precursor (beta APP717) mutants. Science 264, 1336-40

Tanaka S, Nakamura S, Ueda K, Kameyama M, Shiojiri S, Takahashi Y, Kitaguchi N und Ito H (1988): Three types of amyloid protein precursor mRNA in human brain: their differential expression in Alzheimer's disease. Biochem Biophys Res Commun 157, 472-9

Terry RD, Hansen LA, DeTeresa R, Davies P, Tobias H und Katzman R (1987): Senile dementia of the Alzheimer type without neocortical neurofibrillary tangles. J Neuropathol Exp Neurol 누, 262-8

Terry RD, Masliah E, Salmon DP, Butters N, DeTeresa R, Hill R, Hansen LA und Katzman R (1991): Physical basis of cognitive alterations in Alzheimer's disease: synapse loss is the major correlate of cognitive impairment. Ann Neurol $\underline{30}, 572-80$

Tokuda T, Fukushima T, Ikeda S, Sekijima Y, Shoji S, Yanagisawa N und Tamaoka A (1997): Plasma levels of amyloid beta proteins Abeta1-40 and Abeta1-42(43) are elevated in Down's syndrome. Ann Neurol $\underline{41}, 271-3$

Verhey FR (2006): [On the 100th anniversary of Alzheimer's disease]. Ned Tijdschr Geneeskd 150, 2880-2

Vogels OJ, Broere CA, ter Laak HJ, ten Donkelaar HJ, Nieuwenhuys R und Schulte BP (1990): Cell loss and shrinkage in the nucleus basalis Meynert complex in Alzheimer's disease. Neurobiol Aging 11, 3-13 
Wegiel J, Kuchna I, Nowicki K, Frackowiak J, Mazur-Kolecka B, Imaki H, Mehta PD, Silverman WP, Reisberg B, Deleon M, Wisniewski T, Pirttilla T, Frey H, Lehtimaki T, Kivimaki T, Visser FE, Kamphorst W, Potempska A, Bolton D, Currie JR und Miller DL (2007): Intraneuronal Abeta immunoreactivity is not a predictor of brain amyloidosis-beta or neurofibrillary degeneration. Acta Neuropathol $\underline{113}, 389-402$

Weiler R, Lassmann H, Fischer P, Jellinger K und Winkler H (1990): A high ratio of chromogranin A to synaptin/synaptophysin is a common feature of brains in Alzheimer and Pick disease. FEBS Lett $\underline{263}, 337-9$

West MJ (2002): Design-based stereological methods for counting neurons. Prog Brain Res $\underline{135}, 43-51$

West MJ, Kawas CH, Stewart WF, Rudow GL und Troncoso JC (2004): Hippocampal neurons in pre-clinical Alzheimer's disease. Neurobiol Aging 25, 1205-12

West MJ, Slomianka L und Gundersen HJ (1991): Unbiased stereological estimation of the total number of neurons in thesubdivisions of the rat hippocampus using the optical fractionator. Anat Rec 231, 482-97

Weyerer S: Altersdemenz. Gesundheitsberichterstattung des Bundes (Themenheft 28), Robert Koch-Institut. Berlin 2005

Wirths O, Multhaup G, Czech C, Feldmann N, Blanchard V, Tremp G, Beyreuther K, Pradier L und Bayer TA (2002): Intraneuronal APP/A beta trafficking and plaque formation in betaamyloid precursor protein and presenilin-1 transgenic mice. Brain Pathol $\underline{12}$, 275-86

Wirths O, Multhaup G und Bayer TA (2004): A modified beta-amyloid hypothesis: intraneuronal accumulation of the beta-amyloid peptide--the first step of a fatal cascade. $\mathrm{J}$ Neurochem $\underline{91}, 513-20$

www.alzheimer-forschung.de. $\quad$ (2009). "Die Geschichte der Alzheimer-Krankheit." Heruntergeladen am 05. März, 2009, von http://www.alzheimerforschung.de/web/alzheimerkrankheit/geschichte.htm. 
www.alzheimer.de. (2009). "Was ist Alzheimer?" Heruntergeladen am 06. März, 2009, von http://www.alzheimer.de/de/wasistalzheimer/verlauf/page.html.

www.fbs.leeds.ac.uk. (2009). "Alzheimer's Disease." Heruntergeladen am 26.03., 2009, von http://www.fbs.leeds.ac.uk/staff/Hooper N/alzheimers.htm.

Yankner BA, Duffy LK und Kirschner DA (1990): Neurotrophic and neurotoxic effects of amyloid beta protein: reversal by tachykinin neuropeptides. Science $\underline{250}, 279-82$ 


\section{Danksagung}

Ich danke ganz herzlich meinem Doktorvater Herrn Prof. Dr. Bayer für die Bereitstellung des Themas und die gute Betreuung während der gesamten Zeit.

Des Weiteren danke ich den Mitarbeitern aus dem Labor für molekulare Psychiatrie. Im Besonderen gilt mein Dank Ditte Christensen, für die Einarbeitung in den Umgang mit dem Mikroskop. Marie Cotel danke ich für Hilfe bei der Durchführung der Färbungen. Besonders danke ich Dr. Oliver Wirths für die schnelle Hilfe, wenn es technische Probleme mit dem Mikroskop gab.

Gerd Multhaupt danke ich für die Bereitstellung des Antikörpers 23850 gegen humanes APP und Saido Takaomi danke ich für die Bereitstellung der Antikörper N1D und N3pE. 


\section{Lebenslauf:}

Am 03. Mai 1983 wurde ich als erstes Kind meiner Eltern, Mechthild Flohr und Ralf Möller-Flohr (geb. Möller), in Berlin geboren. Ich bin mit meinen Eltern und meiner Schwester Marie-Luise Flohr in Berlin Zehlendorf aufgewachsen, wo ich von 1989 bis 1999 die freie Waldorfschule Emil-Molt besucht habe. Das Schuljahr 1999/2000 verbrachte ich im Rahmen eines Schüleraustausches in den USA im Bundesstaat North Carolina. Nachfolgend wechselte ich im Jahre 2000 zur Oberstufe an die Voltaire-Gesamtschule in Potsdam, wo ich 2003 meine allgemeine Hochschulreife erlangte.

Von 2003 bis 2004 leistete ich Zivildienst im Berufbildungswerk im Oberlinhaus in Potsdam sowie im städtischen Klinikum Oldenburg.

Seit dem Wintersemester 2004 / 2005 studiere ich an der Georg-August-Universität zu Göttingen Humanmedizin. Im August 2006 absolvierte ich den ersten Abschnitt der ärztlichen Prüfung. Mein praktisches Jahr werde ich im Februar 2010 beginnen und voraussichtlich im Frühjahr 2011 zum 2. Abschnitt der ärztlichen Prüfung antreten.

Seit Februar 2008 bin ich der Arbeitsgruppe molekulare Psychiatrie unter der Leitung von Prof. Dr. rer. nat. Thomas Bayer im Rahmen meiner experimentellen Doktorarbeit zum Thema Alzheimer tätig. 